\title{
Deep learning for detecting distresses in buildings and pavements: A critical gap analysis
}

\begin{tabular}{|r|l|}
\hline Journal: & Construction Innovation: Information, Process, Management \\
\hline Manuscript ID & CI-09-2021-0171.R2 \\
\hline Manuscript Type: & Research Article \\
\hline Keywords: & $\begin{array}{l}\text { Deep Learning, Pavement cracks, distresses detection, structural health } \\
\text { evaluation, highway maintenance, CNN }\end{array}$ \\
\hline \multicolumn{2}{|l}{} \\
\end{tabular}

\section{SCHOLARONE \\ Manuscripts}




\title{
Deep learning for detecting distresses in buildings and pavements: A critical gap analysis
}

\begin{abstract}
Purpose: The massive number of pavements and buildings coupled with the limited inspection resources, both monetary and human, to detect distresses and recommend maintenance actions lead to rapid deterioration, decreased service life, lower level of service and increased community disruption. Therefore, this paper aims at providing (1) a state-of-the-art review of the literature with respect to deep learning techniques for detecting distress in both pavements and buildings; (2) research advancements per asset/structure type; and (3) future recommendations in deep learning applications for distress detection.
\end{abstract}

Design/methodology/approach: A critical analysis was conducted on 181 papers of deep learning-based cracks detection. A structured analysis was adopted so that major articles were analyzed according to their focus of study, employed methods, findings and limitations.

Findings: The utilization of deep learning to detect pavement cracks is advanced compared to assess and evaluate the structural health of buildings. There is a need for studies that compare different convolutional neural network $(\mathrm{CNN})$ models to foster the development of an integrated solution that considers the data collection method. Further research is required to examine the setup, implementation, and running costs, frequency of capturing data, and deep learning tool. In conclusion, the future of applying deep learning algorithms in lieu of manual inspection for detecting distresses has shown promising results.

Practical implications: The availability of previous research and the required improvements in the proposed computational tools and models (e.g., artificial intelligence, deep learning, etc.) are triggering researchers and practitioners to enhance the distresses' inspection process and make better use of their limited resources. 
Originality/Value: A critical and structured analysis of deep learning-based crack detection for pavement and buildings is conducted for the first time to enable novice researchers to highlight the knowledge gap in each article, as well as, building a knowledge base from the findings of other research to support developing future workable solutions.

\section{Keywords}

Deep Learning, CNN, Pavement cracks, distresses detection, structural health evaluation, highway maintenance.

\section{Introduction}

The utilization of emerging digital technologies in construction industry is vital to enhance the productivity, as well as, optimizing the utilization of resources (Goulding \& Rahimian, 2012; Pour Rahimian et al., 2008; Elghaish and Abrishami, 2020). One of these technologies is the deep learning.

Traditionally, crack detection is based on manual inspection and dependence on professional's subjectivity. This initiated the need for reliable and efficient crack detection methods to improve the quality of the visual inspection results. Several automated or semiautomated computer-aided crack detection methods have been developed, such as histogram transforms (Patricio et al., 2005), threshold segmentation (Zhu et al., 2007), edge detection (Attoh-Okine \& Ayenu-Prah, 2008; Zhao et al., 2010), region growing (Li et al., 2011; Zhou et al., 2016) etc.

Deep learning, as an extension of and subset to machine learning, has become a new research front in the field of crack detection due to its superior performance in object detection and semantic segmentation (J. Liu et al., 2020a; Abdelkader, 2021). With the evolution of computer-based techniques, the application of deep learning in detecting issues such as cracking where many studies were conducted to demonstrate crack detection using deep learning. To enhance the performance of crack detection, Zhang et al. (2019a) used residual 
network to develop a dilated convolution and multi-branch fusion strategies with different dilation rates. Another application of the deep convolutional neural network (CNN) and laserscanned range images was developed by Zhou \& Song (2020) to realize the pixel-level classification of cracks. Chen \& Jahanshahi (2018) used CNN and Naïve Bayes to analyze individual video frames for crack detection.

Recently, deep learning has greatly endorsed computer vision development, which offers a feasible method for automated crack detection (Ogunseiju et al., 2021). Deep learning allows computers to learn from experience by using artificial neural networks and other machine learning algorithms (Xiong \& Tang, 2021). This technique is 'deep' as it contains many layers that are used for feature extraction, transformation, and pattern analysis using supervised or unsupervised learning (Ongsulee, 2018). The key benefit of deep learning is that it supports a computational model composed of multiple processing layers to learn data representations with multiple levels of abstraction and trains the model on how to update internal parameters through backpropagation, without manual involvement in the design of feature engineering (Goodfellow et al., 2016). Generally, deep learning models contain three types of layers: input later, hidden layer, and output layer. The output of one layer is used as an input into the next one.

There are several architectures that can be implemented when it comes to deep learning (Saadi \& Belhadef, 2019; Mansuri \& Patel, 2021). Each of these architectures has its uses and compatibilities with certain applications. However, it should be noted that convolutional networks (CNNs/ConvNets) are the most common architecture for automated feature learning and supervised classification. CNNs with their capabilities related to the partial connections, sharing weights and pooling layers, can automatically capture the grid-like topology of images under fewer computations, and then generate promising detection results (Cha et al., 2017). $\mathrm{CNN}$ is used in image recognition by inserting the values from the image pixels to identify 
features (Jiang \& Bai, 2020).

The key strength of $\mathrm{CNN}$ is in feature extraction and representation learning and the main weakness is its need for parameter tuning (Da'u \& Salim, 2020). There are variations to the CNN technique such as region-based $\mathrm{CNN}$ (or R-CNN), fast R-CNN, and faster R-CNN. Support vector machine (SVM) was used to classify concrete images to crack and non-crack by using the handcrafted manual feature extraction (Na \& Tao, 2012). Abdel-Qader et al. (2006) combined SVM with principal component analysis (PCA) to extract the healthy features out of a large set of features. Significant improvement to increase the accuracy of crack identification has been recognized after combining hybrid approaches with SVM such as fuzzy logic, genetic algorithm, artificial neural network (ANN), and k-nearest neighbors (k-NN) (Choudhary \& Dey, 2012; Sri Preethaa \& Sabari, 2020). However, the complexity of crack images makes the generalization performance of these traditional algorithms unproductive in efficiently managing a huge volume of cracks image features (Li et al., 2017).

There is a huge demand in the housing market and this requires to adopt unprecedent steps to build the required houses (Kolo et al., 2014). Therefore, Artificial Intelligence including deep learning can help in enhancing the productivity and avoiding rework.

Throughout the last two years, two review papers were published to analyze published deep learning publications in the built environment sector, for example, Akinosho et al. (2020) provided a comprehensive review of the general applications of deep learning in the construction industry, however, deep learning-based detection feature was not critically analysed and many articles have been published since the publication of this article. Given, the fact that the majority of deep learning applications in construction industry are associated with detecting objects including distresses of pavements and concrete and, as far as the authors are aware, there has not been a dedicated study that discusses and analyzes those application to 
enable researchers to enhance the existing solutions.

In lights of all those issues, this paper provides a deep analysis of major published articles of employing deep learning to detect and classify cracks for pavements and buildings. Given, most of published articles focused on utilizing deep learning to detect and classify a wide range of distresses in pavement and buildings, therefore, the objective of this research is to critically analyze published articles by highlighting the focus of each study, employed methods and limitations. As such, novice researchers can start developing workable solutions based on the recommendations of this research.

In accordance with the introductory information provided above, section 2 , the methodology and logic of research is presented, followed by deep learning-based crack detection: a conceptual background is presented in section 3. Convolutional Neural Networks (CNN) for crack detection is described in section 4. Sections 5, 6, 7 and 8 present the critical analysis of deep learning-based crack detection for pavement and buildings, namely, relevant studies for deep learning-based pavement crack detection, deep learning-based concrete cracks detection, deep learning-based health structure evaluation, deep learning and Ground Penetrating Radar (GPR) to detect cracks. Thenceforth, discussion and significance are presented in section 9. Finally, the conclusion is presented in section 10.

\section{Methodology and logic}

stated that the mixed methods systematic review is the most effective method when the objective of the research is to define gaps in the body of knowledge and identify future research trends. Employing mixed methods systematic review enables researchers to form an objective presentation of the field. Mixed methods systematic review studies are superior to monomethod manual review studies in which researchers might be biased and their judgment and interpretation are subjective (He et al., 2017). Besides, relying on mixed methods systematic 
review enhances the depth and breadth of literature review studies (Heyvaert, 2017). 
Figure 1 shows the research design and flow of the data collection and analysis. This paper 
focuses on the utilisation of deep learning to detect cracks/distresses for pavements and 
building structures. Therefore, the keywords that are used are specific such as ( deep AND 
learning AND for AND crack AND detection ) AND ( LIMIT-TO ( DOCTYPE, "ar" )) AND ( LIMIT-TO ( SUBJAREA, "ENGI" ) ) AND ( LIMIT-TO ( EXACTKEYWORD, "Crack Detection" ) OR LIMIT-TO ( EXACTKEYWORD , "Convolutional Neural Networks" ) OR LIMIT-TO ( EXACTKEYWORD, "Damage Detection" ) OR LIMIT-TO ( EXACTKEYWORD, "Neural Networks" ) ) AND ( LIMIT-TO ( SRCTYPE, "j" ) ) AND ( LIMIT-TO ( EXACTSRCTITLE , "Automation In Construction" ) OR LIMIT-TO ( EXACTSRCTITLE, "Computer Aided Civil And Infrastructure Engineering" ).. The results were refined to include Q1 and Q2 Scopus journals to ensure the quality of sources. Given, Scan and skim techniques are recommended to find main themes of articles, as well as, finding relevant articles Machi \& McEvoy (2008), therefore, the results were analysed and classified into two main themes such as 'Deep learning for pavement distresses' and 'Deep learning to
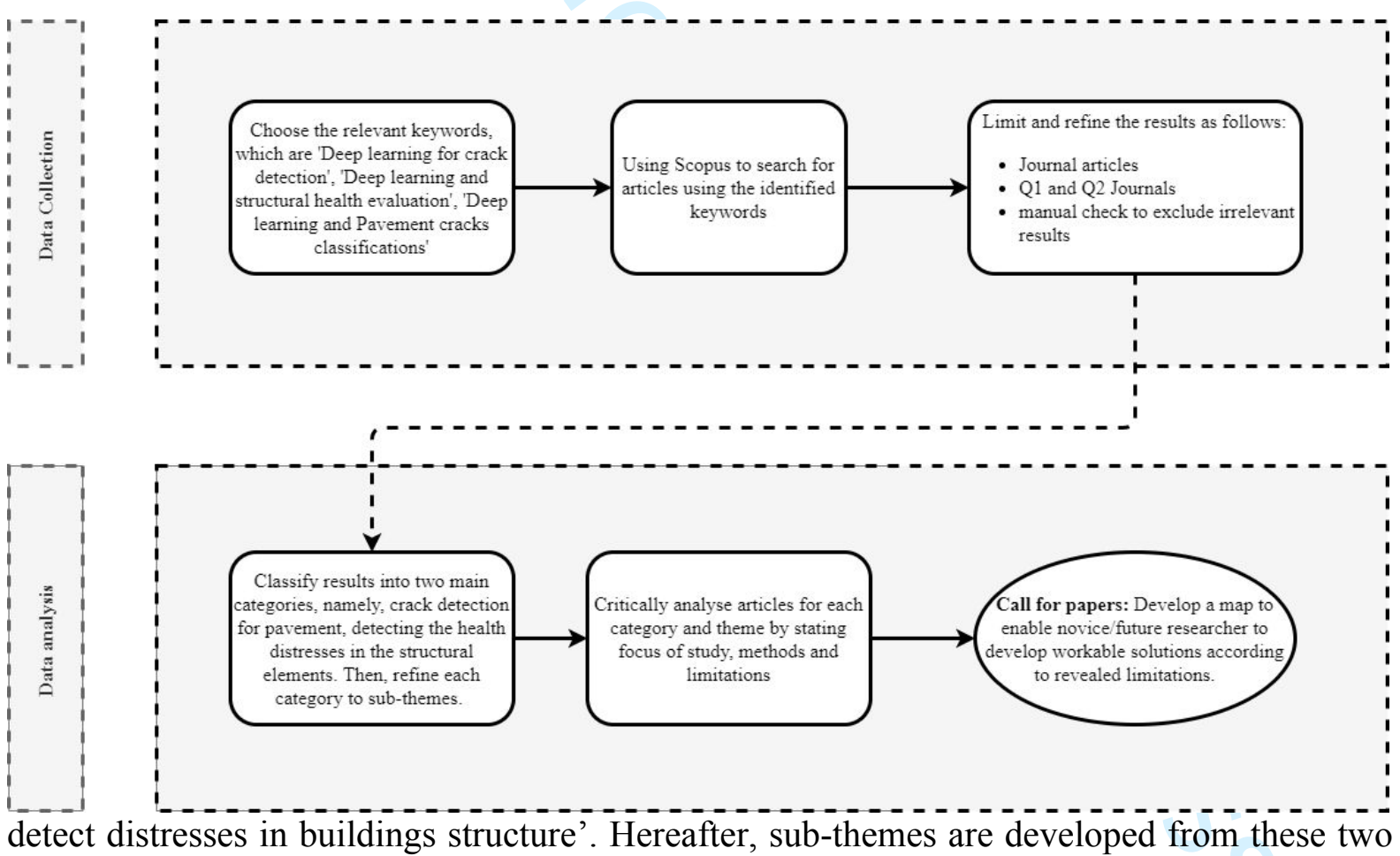

main themes. Most of articles were analysed in specific way, namely, focus of study, employed methods, findings, and the mentioned limitations in each article by authors. To avoid the cognitive bias, the mentioned systematic approach to find and list relevant studies, as well as consistent way of analysing articles were adopted. Moreover, using mentioned limitation(s) by 
articles' authors without judgements.

Figure 1. Research methods and logic

2.1. Deep learning-based crack detection publications per year

Figure 2 shows the number of publications per year. As shown in Figure 2, 181 papers have been published since 2017 and this reflects the high attention the application of deep learning to detect cracks for pavements and buildings has recently received over the past 4 years.

\section{Documents by year}

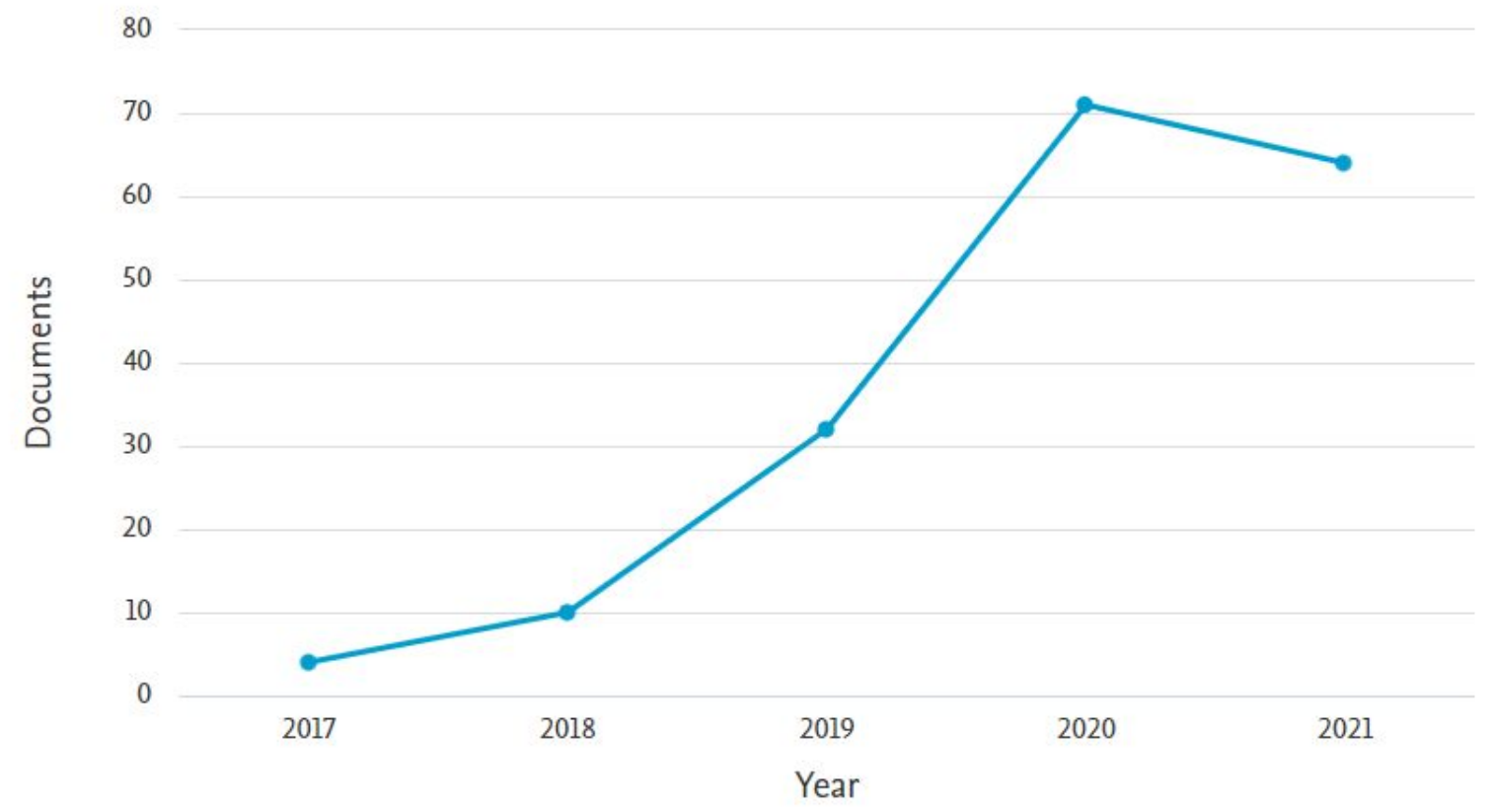

Figure 2. Deep learning-based crack detection publications per year

2.2. Progress of deep learning- based crack detection research per countries

Figure 3 depicts the allocation of 181 papers per countries. Around $45 \%$ of papers come from China, followed by United States that produced around $23 \%$ of total papers. Other $32 \%$ of papers were written in Canada, Australia, Singapore, UK, France, Honk Kong and India. The analysis of geographical allocation of publications works as an indication for future researcher to know the progress of research in this area over the world. 


\section{Documents by country or territory}

Compare the document counts for up to 15 countries/territories.

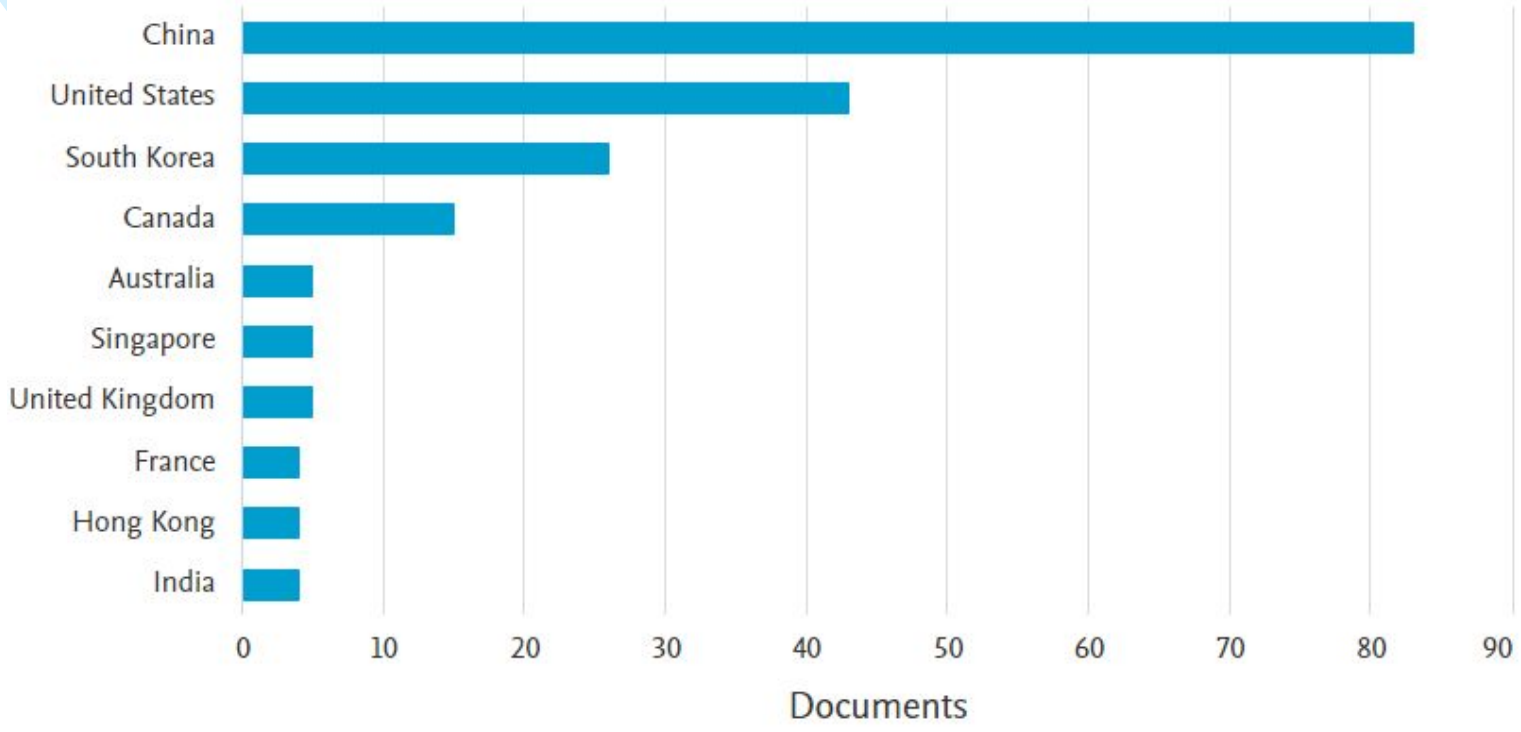

Figure 3. The geographical allocation of publications

\section{Crack detection-based deep learning: A conceptual background}

Deep learning region-based detection methods depend on window-sliding or region-proposal; in which continuous attempts of finding a bounding box for each possible object in an image is the essence of the process. R-CNN (region-based convolutional neural networks) uses selective search to produce regions, and then classifies these regions using a CNN. Cha et al. (2018) combined CNN with the sliding window technique to classify the crack and non-crack images more accurately. Zhang et al. (2018) used an R-CNN model to remove the noise areas before performing crack and sealed crack detection. However, this method (R-CNN) is impractical due to the huge effort required using the window-sliding-based when processing large number of images. In addition, the traditional region-proposal methods are inefficient in selecting good candidate regions from the noisy images (Uijlings et al., 2013). To improve the computation efficacy of region-based methods, H. Zhang et al. (2017) applied parallel processing, however, the computation and resource costs were expensive.

Fast R-CNN and Faster R-CNN improved the speed and accuracy of prediction by using the 
Regional Proposal Network (RPN) to automatically produce the proposal (Ren et al., 2015). To detect cracks of images captured on concrete road surfaces, Hacıefendioğlu \& Başağa (2021) developed a method using a pre-trained Faster R-CNN. Kang et al. (2020) developed an integrated method to automate crack location, segmentation and quantification using the integration of a faster region proposal convolutional neural network (Faster R-CNN) algorithm, modified TuFF method, and modified DTM for the crack detection and localization. Gou et al. (2019) used the Faster-R-CNN model for pavement crack detection. Cha et al. (2018) developed a Faster R-CNN to detect multiple types of damage including concrete cracks. Wang et al. (2018) also used Faster R-CNN for concrete damage detection in masonry historic structures.

Many efforts have been made to implement CNN-related methods in crack detection task, such as U-net convolutional neural networks that was proposed by Zhu et al. (2019) by developing a crack detection algorithm for U-net convolutional neural network, using U-net networks as the front end to extract the crack, and then using threshold method and Dijkstra connection to extract the crack accurately. However, this method was still difficult to solve the problem that features resolution degradation caused by continuous pooling. To increase the details of image features and enhance the effect of dense prediction, an Atrous Spatial Pyramid Pooling (ASPP) module was added to the U-net network by Chen et al. (2017) and Qiao et al. (2021).

Another lightweight end-to-end pixel-wise classification architecture called SegNet is employed by several researchers. For instance, Song et al. (2019) used it to train and test the SegNet model with 2068 bridge cracks images. Chen et al. (2020) applied it for inspecting concrete pavement, asphalt pavement, and bridge deck crack. Jun Zhao et al. (2020) employed it to solve the problems of illumination non-uniformity and impurities in asphalt pavement image. Finally, Ren et al. (2020) utilized it for efficient multiscale feature extraction, aggregation, and resolution reconstruction that greatly enhances the overall crack segmentation 
ability of the network.

CrackNet based on the convolution neural network was presented by A. Zhang et al. (2017) for automatic detection of pavement. CrackNet consists of five layers. The two input data layers are feature maps generated by the feature extractor. The output layer is the set of predicted class scores for all pixels. The two hidden layers are convolutional layers and fully connected layers. CrackNet includes more than one million parameters that are trained in the learning process to improve the accuracy of crack extraction. Inspired by CrackNet, Fei et al. (2020) proposed an automated pixel-level crack detection on 3D asphalt pavement images with deeper architecture and fewer parameters named CrackNet-V. Huyan et al. (2020) developed CrackUnet, which utilises convolution, pooling, transpose convolution, and concatenation operations, forming the "U"-shaped model architecture. Both, CrackNet-V and CrackU-net outperformed CrackNet in term of the calculation accuracy and efficiency.

In this article, a framework for feature selection and classification of cracks images is proposed based on three cascaded phases. The first phase automatically extracts features from the crack images by a CNN model. Then, a proposed feature selection algorithm, using Stochastic Fractal Search (SFS) and Guided Whale Optimization Algorithm (Guided WOA) techniques, is applied to properly select the valuable features. The last phase classifies the selected features by a proposed voting classifier, using Particle Swarm Optimization (PSO) and Guided WOA techniques to improve the ensemble's accuracy.

Huang et al. (2018) developed a two-stream semantic segmentation algorithm to detect crack and leakage in for metro shield tunnel based on deep learning. Feng et al. (2020) proposed a classification-based algorithm to detect cracks of different structures concrete surfaces for crack detection of a concrete dam surface (Cha et al., 2017). A similar method was implemented by Kim \& Cho (2018) who collected images of cracks from the internet web 
search using ScrapeBox and then developed a classification algorithm based on deep neural networks. Other researchers developed a method for crack region segmentation using a mask region-based convolutional neural network (He et al., 2017; Kim \& Cho, 2019).

An integration of a fully convolutional network $(\mathrm{FCN})$ with a Gaussian-conditional random field (G-CRF), an uncertainty framework, and probability-based rejection was proposed by Tong et al. (2020) for detecting pavement defects. Lee et al. (2019) proposed a crack image generation algorithm using a 2D Gaussian kernel and the Brownian motion process to overcome the lack of data problem in crack detection. Jenkins et al. (2018) proposed a deep fully convolutional neural network to perform pixel-wise classification of surface cracks on road and pavement images. A more accurate and efficient crack detection process based on a spatial-channel hierarchical network (SCHNet) with a base net Visual Geometry Group 19 (VGG19), was proposed by Pan et al. (2020) for crack detection. Using the VGG19, Yang et al. (2018) developed a deep learning technique named fully convolutional network (FCN) to improve the efficiency of crack detection task. C. Zhang et al. (2020) developed an automatic pixel-level crack detection network based on instance segmentation to improve the Mask RCNN network, which can output the type, location, and mask of the crack at the same time. A two-step pavement crack detection and segmentation method based on convolutional neural network was proposed by J. Liu et al. (2020b). Ayele et al. (2020) proposed an integrated set of UAV-assisted inspection and automatic damage identification process that comprises three key stages, (i) data collection and model training, (ii) 3D photogrammetry/construction, (iii) crack identification and segmentation, where deep learning-based data analytics and modelling are applied for processing and analysing drone image data and to perform damage assessment. A vision-based crack detection system based on a context-aware deep semantic segmentation network that integrates the pixel-wise prediction results from multiple local overlapping image patches was proposed by Zhang et al. (2019b). A modified architecture of FCNN was proposed 
and employed by $\mathrm{Xu}$ et al. (2019) for crack identification in the steel box girder of bridges containing complicated disturbing background and handwriting. An adversarial learning architecture of Semi-supervised was proposed by Li et al. (2020) and applied for pavement crack detection and by Shim et al. (2020) for Crack Detection in Concrete Structures.

\section{Convolutional Neural Networks (CNN) for crack detection}

Amongst many of the reviewed conventional deep learning architectures, Convolutional Neural Network (CNN) is widely known for their capability of capturing critical local-spatial features, hence producing promising results in crack detection (Cha et al., 2018).

Kumar \& Ghosh (2020) developed a vision- based method using a deep architecture of convolutional neural networks (CNNs) for detecting concrete cracks without calculating the defect features. The designed $\mathrm{CNN}$ is trained on $40 \mathrm{~K}$ images of $256 \times 256$-pixel resolutions to detect cracks by classifying each region separately. Chuang et al. (2019) pre-processed the image by Naive Bayes classifier and then identified cracks with the CNN. Hoang et al. (2018) compared a CNN model with metaheuristic optimized edge detection algorithm. The results of this study showed that the performance of $\mathrm{CNN}$ was significantly better than edge detector. A later study by Ye et al. (2019) put forward a structural crack detection method based on CNN, which divides the image and processes it with deep $\mathrm{NN}$ and random forest. However, the region-based methods can only provide information on the existence of cracks and rough shape and location depending on the size of regions. The value of crack detection decreases if the accurate pattern and location of the cracks cannot be given. Liang (2019) introduced a CNN approach for detecting concrete columns surface cracks or spalls. To overcome this issue, pixellevel crack detection methods are studied. For instance, the investigation conducted by Fan et al. (2019) improved the detection accuracy to $92.08 \%$ through the integration between the edge optimization algorithm and the CNN. Ni et al. (2019) proposed a convolutional neural 
network-based framework to automatically extract cracks and accurately at a pixel level, through convolutional feature fusion and pixel-level classification. Liu \& Zhang (2020) presented a novel context-aware deep convolutional semantic segmentation network to effectively detect cracks in structural infrastructure under various conditions. The proposed method applies a pixel-wise deep semantic segmentation network to segment the cracks on images with arbitrary sizes without retraining the prediction network. Meanwhile, a context-aware fusion algorithm that leverages local cross-state and cross-space constraints was proposed by Won et al. (2020) to fuse the predictions of image patches through the adoption of U-Net to detect the concrete cracks. Focal loss function is selected as the evaluation function, and the Adam algorithm is applied for optimization. The trained U-Net is able to identify the crack locations from the input raw images under various conditions such as illumination, messy background, width of cracks, etc. with high effectiveness and robustness. Fan et al. (2020) developed a robust method for crack detection using the concept of transfer learning as an alternative to training an original neural network. Three standard deep learning methods of training a crack classifier are as follows: 1) a shallow convolutional neural network built from scratch, 2) the output features of the VGG16 network architecture previously trained on the general ImageNet dataset, and 3) the fine-tuned top layer of VGG16 is investigated. Data augmentation is used to reduce overfitting caused by the limited and imbalanced training dataset. The image dataset includes both fatigue test photographs and actual inspection photographs captured under uncontrolled distance, lighting, angle, and blurriness conditions. Zhu \& Song (2020) developed a weakly supervised network for the segmentation and detection of cracks in asphalt concrete deck. Firstly, the data were differentiated by the autoencoder, and the unlabeled data features were highlighted, so that the original data autonomously generate a weakly supervised start point for convergence. Secondly, the features were classified by kmeans clustering (KMC). Thirdly, the cracks in the bridge deck defects images was subjected 
to semantic segmentation under weak supervision. A dataset of six types of defects on asphalt concrete bridge deck, which was set up the defects in the dataset, was labelled manually. Recent research utilized cycle consistent generative adversarial learning for crack detection (Nath et al., 2020). In this study, the authors proposed a self-supervised structure learning network that can be trained without using neither paired data nor ground truths (GTs). This is achieved by training an additional reverse network to translate the output back to the input simultaneously.

In recent years, there has been an increasing interest in Whale Optimization Algorithm (WOA) that was proposed by Mirjalili \& Lewis (2016). The concept of the WOA is inspired by the foraging behavior of whales. Bubbles are utilised to catch the prey by pushing them to the surface in a spiral shaped (Mirjalili \& Lewis, 2016; Mirjalili et al., 2020). Recently, literature showed that WOA has a significant capacity in resolving complicated engineering optimization problems (Ling et al., 2017). Abdel-Basset et al. (2018) proposed a combination of WOA and a local search strategy to tackle the permutation flow shop scheduling problem. Mafarja \& Mirjalili (2017) combined WOA with simulated annealing for feature extraction. Aljarah et al. (2018) proposed WOA-based trainer to train multilayer perceptron (MLP) neural networks. Moreover, there are also research bodies trying to utilise WOA to solve other problems, such as multi-objective optimization (Wang et al., 2017; Aziz et al., 2018; Got et al., 2020), image processing (Hassanien et al., 2017; Mostafa et al., 2017; Aziz et al., 2018), software testing (Harikarthik et al., 2019), and power system applications (Hasanien, 2018; Raj \& Bhattacharyya, 2018). To implement this algorithm, three mechanisms should be modeled: (1) shrinking encircling prey, (2) bubble-net attacking method (exploitation phase) and (3) search for prey (exploration phase). The first mechanism is the prey encircling when the WOA initiates the best search agent by considering the current locations as the best location of the prey. The remaining agents accordingly adjust their locations to the best search agent. This can be expressed mathematically as stated by (Mirjalili \& Lewis, 2016). 


\section{Relevant studies for deep learning-based pavement crack detection}

Table 1 shows the major published research from 2017 to 2021 that focus on using deep learning to detect and classify cracks for pavement. Each paper was analyzed according to research aim (focus of study), methods, findings, and limitations to enable researchers to develop new solutions to address those limitations.

Table 1. Relevant research for deep learning-based pavement crack detection

\begin{tabular}{|c|c|c|c|c|}
\hline Authors & Aim & Methodology & Findings & Limitation(s) \\
\hline $\begin{array}{l}\text { (Ali et al., } \\
2021 \text { ) }\end{array}$ & $\begin{array}{l}\text { Provide a reference } \\
\text { for researchers } \\
\text { working in the field } \\
\text { of crack detection } \\
\text { and localization in } \\
\text { concrete structures. }\end{array}$ & $\begin{array}{l}\text { Applying five deep } \\
\text { learning models, } \\
\text { including a proposed } \\
\text { customized CNN } \\
\text { model, }\end{array}$ & $\begin{array}{l}\text { Training a customized } \\
\text { CNN } \\
\text { model with a small } \\
\text { amount of data and high } \\
\text { performance is the best } \\
\text { option for practical crack } \\
\text { detection in concrete } \\
\text { surfaces. }\end{array}$ & $\begin{array}{l}\text { Customized CNN } \\
\text { model is not able to } \\
\text { analyze various } \\
\text { characteristic of } \\
\text { cracks, such as } \\
\text { crack width, length, } \\
\text { and orientation. }\end{array}$ \\
\hline $\begin{array}{l}\text { (Chun et } \\
\text { al., 2021) }\end{array}$ & $\begin{array}{l}\text { Overcome } \\
\text { Weaknesses in } \\
\text { Images and } \\
\text { GIS Visualization } \\
\text { for the detection of } \\
\text { cracks in Asphalt } \\
\text { pavement. }\end{array}$ & $\begin{array}{l}\text { Using a } \\
\text { convolutional neural } \\
\text { network (CNN). }\end{array}$ & $\begin{array}{l}\text { The model developed in } \\
\text { this study showed high } \\
\text { detection accuracy for } \\
\text { pavement images with } \\
\text { cracks. }\end{array}$ & $\begin{array}{l}\text { Few false positives } \\
\text { in pavement images } \\
\text { without cracks } \\
\text { caused by slender } \\
\text { shadows and joints. }\end{array}$ \\
\hline $\begin{array}{l}\text { (Le et al., } \\
\text { 2021)) }\end{array}$ & $\begin{array}{l}\text { Classify the cracked } \\
\text { images efficiently, } \\
\text { saving time, and } \\
\text { avoiding high } \\
\text { computational costs. }\end{array}$ & $\begin{array}{l}\text { Image-based CNN } \\
\text { recognition model } \\
\text { for the detection of } \\
\text { cracks on concrete } \\
\text { surfaces. }\end{array}$ & $\begin{array}{l}\text { The proposed CNN model } \\
\text { improves the } \\
\text { classification of cracked } \\
\text { images. }\end{array}$ & $\begin{array}{l}\text { Different types of } \\
\text { cracks were not } \\
\text { considered in this } \\
\text { works. }\end{array}$ \\
\hline $\begin{array}{l}\text { (Yang et } \\
\text { al., 2021) }\end{array}$ & $\begin{array}{l}\text { Compare the } \\
\text { superiority of the } \\
\text { training model } \\
\text { according to the test } \\
\text { set; and then select } \\
\text { the most suitable } \\
\text { model based on the } \\
\text { experimental results }\end{array}$ & $\begin{array}{l}\text { Three neural } \\
\text { networks, AlexNet, } \\
\text { VGGNet13, and } \\
\text { ResNet18, to } \\
\text { recognize and } \\
\text { classify crack } \\
\text { images. }\end{array}$ & $\begin{array}{l}\text { The tests indicate that the } \\
\text { ResNet } 18 \\
\text { model generates the most } \\
\text { satisfactory results. }\end{array}$ & $\begin{array}{l}\text { Comparison is } \\
\text { limited to three } \\
\text { neural networks. }\end{array}$ \\
\hline $\begin{array}{l}\text { (Rao et } \\
\text { al., 2021) }\end{array}$ & $\begin{array}{l}\text { Detect crack/non- } \\
\text { crack conditions of } \\
\text { concrete structures } \\
\text { from images. }\end{array}$ & $\begin{array}{l}\text { Automated detection } \\
\text { method based on } \\
\text { CNN models and } \\
\text { non-overlapping } \\
\text { window-based } \\
\text { approach. }\end{array}$ & $\begin{array}{l}\text { The proposed approach } \\
\text { outperforms existing } \\
\text { models in terms of } \\
\text { accuracy and inference } \\
\text { time. }\end{array}$ & $\mathrm{N} / \mathrm{A}$ \\
\hline (Zhou \& & Yield better & DCNN-based & The experimental cases & Difficulty in \\
\hline
\end{tabular}


wise separable

convolution.

\begin{tabular}{|c|c|c|c|c|}
\hline $\begin{array}{l}\text { (Zhang et } \\
\text { al., 2018) }\end{array}$ & $\begin{array}{l}\text { Develop an } \\
\text { ImageNet-based } \\
\text { pre-trained model to } \\
\text { identify cracks and } \\
\text { seal cracks } \\
\text { in pavement images. }\end{array}$ & $\begin{array}{l}\text { Training a DCNN to } \\
\text { pre classify a } \\
\text { pavement image, } \\
\text { and a block wise } \\
\text { thresholding method } \\
\text { to segment the } \\
\text { crack/sealed crack } \\
\text { pixels and tensor } \\
\text { voting-based curve } \\
\text { detection to extract } \\
\text { the crack/sealed } \\
\text { crack. }\end{array}$ & $\begin{array}{l}\text { The proposed approach } \\
\text { accurately distinguishes } \\
\text { cracks from sealed cracks } \\
\text { and achieves very good } \\
\text { detection performance. }\end{array}$ & N/A \\
\hline $\begin{array}{l}\text { (Yang et } \\
\text { al., 2018) }\end{array}$ & $\begin{array}{l}\text { Develop a } \\
\text { novel approach for } \\
\text { automatic detection } \\
\text { and measurement of } \\
\text { pixel-level cracked } \\
\text { concrete } \\
\text { structures. }\end{array}$ & $\begin{array}{l}\text { Deep learning } \\
\text { approach, named } \\
\text { fully convolutional } \\
\text { network (FCN). The } \\
\text { architecture was } \\
\text { composed of down } \\
\text { sampling } \\
\text { (conventional CNN } \\
\text { layers) and up } \\
\text { sampling } \\
\text { (Deconvolutional } \\
\text { layer). }\end{array}$ & $\begin{array}{l}\text { The results show that } \\
\text { FCN is feasible and } \\
\text { sufficient for crack } \\
\text { identification and } \\
\text { measurement. }\end{array}$ & $\begin{array}{l}\text { The accuracy is not } \\
\text { as high as CrackNet. }\end{array}$ \\
\hline $\begin{array}{l}\text { (Cha et } \\
\text { al., 2017) }\end{array}$ & $\begin{array}{l}\text { Detect concrete } \\
\text { cracks without } \\
\text { calculating the } \\
\text { defect features. }\end{array}$ & $\begin{array}{l}\text { Vision-based } \\
\text { method using a deep } \\
\text { architecture of } \\
\text { convolutional neural } \\
\text { networks (CNNs) } \\
\text { with sliding window } \\
\text { techniques }\end{array}$ & $\begin{array}{l}\text { The proposed method } \\
\text { shows quite better } \\
\text { performances especially } \\
\text { in detecting thin cracks } \\
\text { under lighting conditions. }\end{array}$ & $\begin{array}{l}\text { Implementations of } \\
\text { IPTs and CNNs, is } \\
\text { incapable of sensing } \\
\text { internal features due } \\
\text { to the nature of } \\
\text { photographic } \\
\text { images. }\end{array}$ \\
\hline $\begin{array}{l}\text { (Wang et } \\
\text { al., 2017) }\end{array}$ & $\begin{array}{l}\text { Propose an approach } \\
\text { to pavement } \\
\text { cracking detection } \\
\text { based on the } \\
\text { learning from a } \\
\text { large and diverse set } \\
\text { of example data for } \\
\text { a better } \\
\text { consideration on } \\
\text { the complexity and } \\
\text { diversity of } \\
\text { pavement surfaces. }\end{array}$ & $\begin{array}{l}\text { CNN } \\
\text { architecture with } \\
\text { three convolutional } \\
\text { and two fully } \\
\text { connected layers for } \\
\text { asphalt pavement } \\
\text { crack recognition. }\end{array}$ & $\begin{array}{l}\text { The proposed CNN is } \\
\text { progressively improved, } \\
\text { and the generalization is } \\
\text { also enhanced. It is } \\
\text { demonstrated that the } \\
\text { trained CNN can achieve } \\
\text { high accuracies } 96.32 \text { and } \\
94.29 \% \text { on training data } \\
\text { and testing data } \\
\text { respectively. }\end{array}$ & $\begin{array}{l}\text { The proposed CNN } \\
\text { recognizes cracks in } \\
\text { image cells instead } \\
\text { of detecting them at } \\
\text { pixel level. }\end{array}$ \\
\hline
\end{tabular}

\section{Deep learning-based concrete and steel cracks detection}

Given the fact that this research focuses on analyzing major published articles for deep learning-based crack detection for both pavement and buildings, Table 2 presents the analysis of key articles that include application of using deep learning to detect cracks for buildings.

Table 2. Key articles for deep learning-based buildings and steel structures cracks detection 


\begin{tabular}{|c|c|c|c|c|}
\hline Author & Aim & Methodology & Findings & Limitation(s) \\
\hline $\begin{array}{l}\text { (Chow et al., } \\
\text { 2020) }\end{array}$ & $\begin{array}{l}\text { This study } \\
\text { presents an AI- } \\
\text { empowered } \\
\text { inspection } \\
\text { pipeline to } \\
\text { streamline the } \\
\text { visual inspection } \\
\text { of the of concrete } \\
\text { defects of civil } \\
\text { infrastructure. }\end{array}$ & $\begin{array}{l}\text { Using deep } \\
\text { learning image- } \\
\text { based } \\
\text { inspection }\end{array}$ & $\begin{array}{l}\text { The proposed } \\
\text { CNN model can } \\
\text { detect a wide } \\
\text { range of defects } \\
\text { under different } \\
\text { environmental } \\
\text { conditions. }\end{array}$ & $\begin{array}{l}\text { Limitations in } \\
\text { detecting long and } \\
\text { narrow cracks, } \\
\text { identifying defects } \\
\text { in patches of low } \\
\text { contrast and } \\
\text { sharpness, and } \\
\text { misclassifying } \\
\text { rough healthy } \\
\text { concrete surfaces } \\
\text { as spalled } \\
\text { regions }\end{array}$ \\
\hline $\begin{array}{l}\text { (C. Zhang et } \\
\text { al., 2020) }\end{array}$ & $\begin{array}{l}\text { This study aims } \\
\text { to develop a } \\
\text { vision-based } \\
\text { approach for } \\
\text { detecting multiple } \\
\text { surface damages } \\
\text { in concrete } \\
\text { highway bridges. }\end{array}$ & $\begin{array}{l}\text { Using Real-time } \\
\text { objection detection } \\
\text { technique and You } \\
\text { Only Look One } \\
\text { (YOLOv3), }\end{array}$ & $\begin{array}{l}\text { The developed } \\
\text { algorithm can } \\
\text { detect concrete } \\
\text { crack, pop-out, } \\
\text { spalling, and } \\
\text { exposed rebar. }\end{array}$ & $\begin{array}{l}\text { The dataset } \\
\text { contains many } \\
\text { small damages and } \\
\text { complex } \\
\text { background } \\
\text { information, which } \\
\text { could inhibit the } \\
\text { algorithms' } \\
\text { generalization and } \\
\text { capacity. }\end{array}$ \\
\hline $\begin{array}{l}\text { (Dorafshan \& } \\
\text { Azari, 2020) }\end{array}$ & $\begin{array}{l}\text { This study aims } \\
\text { to investigate the } \\
\text { feasibility of } \\
\text { using deep } \\
\text { learning models } \\
\text { in detecting } \\
\text { subsurface } \\
\text { defects and } \\
\text { overlay } \\
\text { debonding from } \\
\text { impact echo (IE) } \\
\text { data. }\end{array}$ & $\begin{array}{l}\text { Using one- and } \\
\text { two-dimensional } \\
\text { convolutional } \\
\text { neural network } \\
(\mathrm{CNN}) .\end{array}$ & $\begin{array}{l}\text { Results show that } \\
\text { the proposed 1D } \\
\text { CNN was the } \\
\text { most efficient in } \\
\text { detecting } \\
\text { debonding and } \\
\text { subsurface } \\
\text { defects. }\end{array}$ & $\begin{array}{l}\text { Training dataset is } \\
\text { limited. }\end{array}$ \\
\hline $\begin{array}{l}\text { (Fiorillo \& } \\
\text { Nassif, 2020) }\end{array}$ & $\begin{array}{l}\text { This study } \\
\text { presents a } \\
\text { procedure that } \\
\text { allows bridge } \\
\text { engineers to } \\
\text { estimate health } \\
\text { index } \\
\text { deterioration rates } \\
\text { for bridge } \\
\text { elements. }\end{array}$ & $\begin{array}{l}\text { Using deep } \\
\text { convolutional } \\
\text { neural networks } \\
\text { and NBI historic } \\
\text { data. }\end{array}$ & $\begin{array}{l}\text { The proposed } \\
\text { approach better } \\
\text { estimates NBI } \\
\text { ratings from } \\
\text { bridge element } \\
\text { conditions. }\end{array}$ & $\begin{array}{l}\text { Bridge elements } \\
\text { data are still } \\
\text { limited. }\end{array}$ \\
\hline $\begin{array}{l}\text { (Ghosh } \\
\text { Mondal et al., } \\
\text { 2020) }\end{array}$ & $\begin{array}{l}\text { This study aims } \\
\text { to assess multiple } \\
\text { damage } \\
\text { categories in } \\
\text { reinforced } \\
\text { concrete } \\
\text { buildings due to } \\
\text { an earthquake } \\
\text { from visual data } \\
\text { captured by the } \\
\text { sensors mounted } \\
\text { on the robots. }\end{array}$ & $\begin{array}{l}\text { Using four } \\
\text { different CNN } \\
\text { architectures, } \\
\text { namely, Inception } \\
\text { v2, ResNet-50, } \\
\text { ResNet-101, and } \\
\text { Inception-ResNet- } \\
\text { v2 }\end{array}$ & $\begin{array}{l}\text { Inception-ResNet- } \\
\text { v2 was found to } \\
\text { perform better } \\
\text { (producing a } \\
\text { MAP value of } \\
60.8 \% \text { ) compared } \\
\text { to Inception v2, } \\
\text { ResNet-50 and } \\
\text { ResNet-101. } \\
\text { Also, it was found } \\
\text { that the } \\
\text { processing speed } \\
\text { reduces with }\end{array}$ & $\begin{array}{l}\text { The wide-ranging } \\
\text { camera } \\
\text { specifications } \\
\text { leading to huge } \\
\text { variations in image } \\
\text { resolution and } \\
\text { quality, which may } \\
\text { potentially affect } \\
\text { the performance of } \\
\text { the proposed } \\
\text { neural network- } \\
\text { based approach. }\end{array}$ \\
\hline
\end{tabular}




\begin{tabular}{|c|c|c|c|c|}
\hline & & & $\begin{array}{l}\text { increase in } \\
\text { accuracy. }\end{array}$ & \\
\hline $\begin{array}{l}\text { (Kim et al., } \\
\text { 2020) }\end{array}$ & $\begin{array}{l}\text { This study } \\
\text { presents a } \\
\text { methodology for } \\
\text { automated bridge } \\
\text { component } \\
\text { recognition in 3D } \\
\text { point cloud data. }\end{array}$ & $\begin{array}{l}\text { Using deep } \\
\text { learning in } \\
\text { conjunction with } \\
\text { subspace partition. }\end{array}$ & $\begin{array}{l}\text { The proposed } \\
\text { methodology is } \\
\text { capable for robust } \\
\text { and automated } \\
\text { bridge component } \\
\text { recognition from } \\
\text { 3D point clouds } \\
\text { of the full-scale } \\
\text { bridges. }\end{array}$ & $\begin{array}{l}\text { Unable to evaluate } \\
\text { surface damages } \\
\text { on the point cloud. }\end{array}$ \\
\hline $\begin{array}{l}\text { (Ali \& Cha, } \\
\text { 2019) }\end{array}$ & $\begin{array}{l}\text { This study } \\
\text { presents an } \\
\text { approach to } \\
\text { automatically } \\
\text { detecting } \\
\text { subsurface } \\
\text { damage on } \\
\text { steel bridge } \\
\text { members. }\end{array}$ & $\begin{array}{l}\text { By integrating } \\
\text { infrared } \\
\text { thermography } \\
\text { (IRT) with the } \\
\text { original deep } \\
\text { inception } \\
\text { neural network } \\
\text { (DINN) }\end{array}$ & $\begin{array}{l}\text { The developed } \\
\text { method can } \\
\text { accurately detect } \\
\text { subsurface } \\
\text { damage in those } \\
\text { structural } \\
\text { elements using } \\
\text { thermal images } \\
\text { and reduce } \\
\text { computational } \\
\text { costs. }\end{array}$ & $\begin{array}{l}\text { The proposed } \\
\text { method cannot } \\
\text { differentiate the } \\
\text { different } \\
\text { types of damages. }\end{array}$ \\
\hline $\begin{array}{l}\text { (Kim \& Cho, } \\
\text { 2019) }\end{array}$ & $\begin{array}{l}\text { This paper } \\
\text { presents a crack } \\
\text { assessment } \\
\text { framework for } \\
\text { concrete } \\
\text { structures that } \\
\text { detects and } \\
\text { quantifies cracks. }\end{array}$ & $\begin{array}{l}\text { Using Mask and } \\
\text { region-based CNN } \\
\text { (Mask R-CNN). }\end{array}$ & $\begin{array}{l}\text { The proposed } \\
\text { framework } \\
\text { Detects most of } \\
\text { the cracks } 0.3 \mathrm{~mm} \\
\text { or wider and } \\
\text { quantifies cracks } \\
\text { with widths of } 0.3 \\
\text { mm or more with } \\
\text { errors less than } \\
0.1 \mathrm{~mm} \text {. }\end{array}$ & $\begin{array}{l}\text { Cracks less than } \\
0.3 \text { mm widths } \\
\text { show relatively } \\
\text { larger error due } \\
\text { image resolution. }\end{array}$ \\
\hline (Liang, 2019) & $\begin{array}{l}\text { This study } \\
\text { presents a three- } \\
\text { level image-based } \\
\text { approach for } \\
\text { post-disaster } \\
\text { inspection of the } \\
\text { reinforced } \\
\text { concrete bridge. }\end{array}$ & $\begin{array}{l}\text { Using } \\
\text { convolutional } \\
\text { neural network, } \\
\text { object detection, } \\
\text { and semantic } \\
\text { segmentation. }\end{array}$ & $\begin{array}{l}\text { Results show that } \\
\text { all three-level } \\
\text { deep learning } \\
\text { models are very } \\
\text { promising in } \\
\text { terms of } \\
\text { accuracies and } \\
\text { robustness. }\end{array}$ & set \\
\hline $\begin{array}{l}\text { (Li et al., } \\
\text { 2019) }\end{array}$ & $\begin{array}{l}\text { Develop a } \\
\text { damage detection } \\
\text { method to detect } \\
\text { four concrete } \\
\text { damages: cracks, } \\
\text { spalling, } \\
\text { efflorescence, and } \\
\text { hole. }\end{array}$ & $\begin{array}{l}\text { Using Fully } \\
\text { Convolutional } \\
\text { Network (FCN) }\end{array}$ & $\begin{array}{l}\text { The proposed } \\
\text { FCN was strong } \\
\text { at detecting } \\
\text { concrete } \\
\text { damages: cracks, } \\
\text { spalling, } \\
\text { efflorescence, and } \\
\text { holes, and showed } \\
\text { low levels of } \\
\text { noise. }\end{array}$ & $\begin{array}{l}\text { The inability to } \\
\text { detect the depth of } \\
\text { damages. }\end{array}$ \\
\hline
\end{tabular}

\section{Deep learning-based health structure evaluation}

Table 3 shows the relevant studies that developed deep learning models to evaluate the structural health of existing buildigs, therefore, novice researchers can use mentioned 
limitations in these studies to develop solutions to bridge gap and foster the implemenattion of Artifitiial Intelligence (AI) for construction industry

Table 3. Deep learning-based structural health evaluations of buildings

\begin{tabular}{|c|c|c|c|c|}
\hline Author & Aim & Methodology & Findings & Limitation \\
\hline $\begin{array}{l}\text { (Bae et al., } \\
\text { 2021) }\end{array}$ & $\begin{array}{l}\text { The study presents } \\
\text { a deep super } \\
\text { resolution crack } \\
\text { network (SrcNet) } \\
\text { to improve crack } \\
\text { detectability } \\
\text { during automated } \\
\text { interpretation of } \\
\text { digital images. }\end{array}$ & $\begin{array}{l}\text { Using CNN-based } \\
\text { Super Resolution } \\
\text { (SR) technique } \\
\text { combined with the } \\
\text { semantic } \\
\text { segmentation }\end{array}$ & $\begin{array}{l}\text { Results show that } \\
\text { the crack } \\
\text { detectability of } \\
\text { SrcNet was } \\
\text { remarkably } \\
\text { increased in terms } \\
\text { of recall }\end{array}$ & $\begin{array}{l}\text { Comparing with } \\
\text { the crack detection } \\
\text { results using raw } \\
\text { digital images, } \\
\text { positive false } \\
\text { alarms were } \\
\text { inversely } \\
\text { increased }\end{array}$ \\
\hline $\begin{array}{l}\text { (Sajedi \& } \\
\text { Liang, } \\
\text { 2021) }\end{array}$ & $\begin{array}{l}\text { The study aims to } \\
\text { leverage on deep } \\
\text { Bayesian neural } \\
\text { networks for } \\
\text { vision-based } \\
\text { structural } \\
\text { inspections. }\end{array}$ & $\begin{array}{l}\text { Using Bayesian } \\
\text { inference and } \\
\text { Monte Carlo } \\
\text { dropout sampling. } \\
\text {. }\end{array}$ & $\begin{array}{l}\text { Bayesian inference } \\
\text { can be an effective } \\
\text { tool to make visual } \\
\text { inspections using } \\
\text { deep vision } \\
\text { models. }\end{array}$ & $\begin{array}{l}\text { Differences } \\
\text { between the } \\
\text { distribution } \\
\text { patterns of entropy } \\
\text { and MCSSD are } \\
\text { observed. }\end{array}$ \\
\hline $\begin{array}{l}\text { (Dong et al., } \\
2020 \text { ) }\end{array}$ & $\begin{array}{l}\text { This study } \\
\text { proposes a method } \\
\text { to achieve non- } \\
\text { contact } \\
\text { displacement } \\
\text { monitoring for } \\
\text { civil structures } \\
\text { with less user } \\
\text { involvement }\end{array}$ & $\begin{array}{l}\text { Using deep } \\
\text { learning-based full } \\
\text { field optical flow } \\
\text { methods. }\end{array}$ & $\begin{array}{l}\text { Results show that } \\
\text { the proposed } \\
\text { method gives } \\
\text { higher accuracy } \\
\text { than the traditional } \\
\text { optical flow } \\
\text { algorithm. }\end{array}$ & $\begin{array}{l}\text { Background } \\
\text { clutter should be } \\
\text { avoided to } \\
\text { increase the } \\
\text { accuracy of the } \\
\text { flow prediction of } \\
\text { the measurement. }\end{array}$ \\
\hline $\begin{array}{l}\text { (Gonzalez et } \\
\text { al., 2020) }\end{array}$ & $\begin{array}{l}\text { This study } \\
\text { explores the } \\
\text { potential of using } \\
\text { a CNN to classify } \\
\text { buildings } \\
\text { according to their } \\
\text { lateral load- } \\
\text { resisting system }\end{array}$ & $\begin{array}{l}\text { CNN in the dataset } \\
\text { of nearly } 10000 \\
\text { manually annotated } \\
\text { photos at the street } \\
\text { level. }\end{array}$ & $\begin{array}{l}\text { The study results } \\
\text { showed a precision } \\
\text { of } 93 \% \text { and a } \\
\text { recall of } 95 \% \\
\text { when identifying } \\
\text { nonductile } \\
\text { buildings. }\end{array}$ & $\begin{array}{l}\text { Misclassifications } \\
\text { occur at the } \\
\text { typology level. }\end{array}$ \\
\hline $\begin{array}{l}\text { (Kohiyama } \\
\text { et al., 2020) }\end{array}$ & $\begin{array}{l}\text { This study } \\
\text { presents a method } \\
\text { to detect unlearned } \\
\text { damage patterns } \\
\text { for structural } \\
\text { health monitoring }\end{array}$ & $\begin{array}{l}\text { Using the collective } \\
\text { decision of support } \\
\text { vector machines } \\
\text { (SVMs). }\end{array}$ & $\begin{array}{l}\text { The method can } \\
\text { automatically } \\
\text { recognize specific } \\
\text { features for } \\
\text { classifying damage } \\
\text { patterns of a target } \\
\text { structure with high } \\
\text { accuracy. }\end{array}$ & $\begin{array}{l}\text { The simulation } \\
\text { model } \\
\text { discordance. }\end{array}$ \\
\hline
\end{tabular}




\begin{tabular}{|c|c|c|c|c|}
\hline $\begin{array}{l}\text { (T. Zhang et } \\
\text { al., 2020) }\end{array}$ & $\begin{array}{l}\text { This study } \\
\text { presents a new } \\
\text { method for a } \\
\text { challenging } \\
\text { structural } \\
\text { condition } \\
\text { identification. }\end{array}$ & $\begin{array}{l}\text { Based on a deep } \\
\text { learning network } \\
\text { architecture Alex- } \\
\text { Net. }\end{array}$ & $\begin{array}{l}\text { The results show } \\
\text { that the proposed } \\
\text { method is efficient } \\
\text { and consistent in } \\
\text { structural } \\
\text { condition } \\
\text { identification. }\end{array}$ & $\begin{array}{l}\text { The sensor } \\
\text { location is a key } \\
\text { factor that may } \\
\text { influence the } \\
\text { algorithm } \\
\text { performance. }\end{array}$ \\
\hline
\end{tabular}

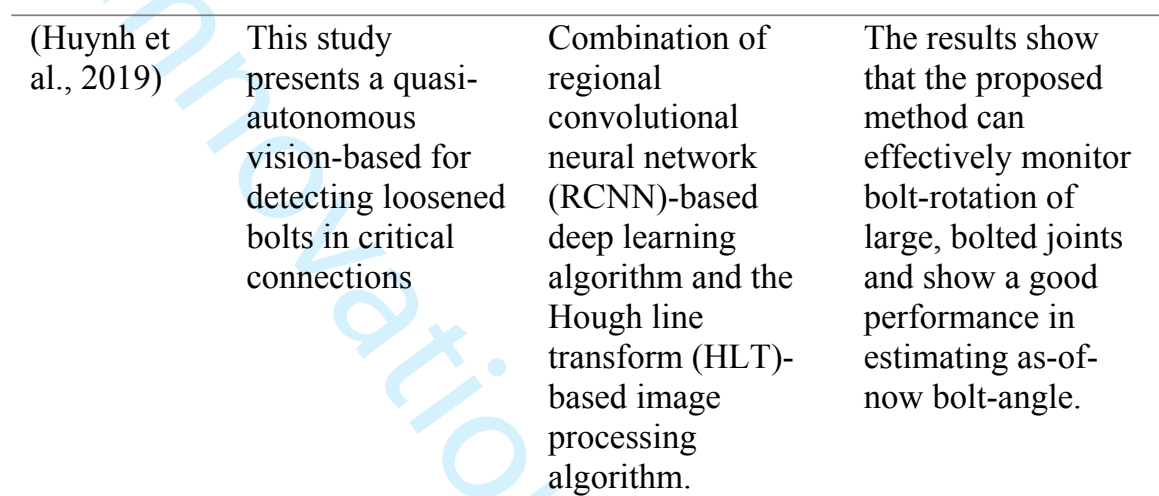

The proposed method can only provide the rotational angle of the bolt, not the preload loss happening in the bolt.

\begin{tabular}{ll}
\hline (Ni et al., & This study \\
presents an \\
efficient \\
image-based \\
structural damage \\
detection and \\
segmentation \\
method at the \\
pixel level for \\
structural crack \\
delineation.
\end{tabular}

\begin{tabular}{|c|c|c|}
\hline $\begin{array}{l}\text { By employing a } \\
\text { feature pyramid } \\
\text { network (FPN) and } \\
\text { a generic pretrained } \\
\text { CNN model, } \\
\text { GoogLeNet CNN. }\end{array}$ & $\begin{array}{l}\text { The results show } \\
\text { that the proposed } \\
\text { method can } \\
\text { delineate cracks } \\
\text { accurately and } \\
\text { rapidly. }\end{array}$ & $\begin{array}{l}\text { The delineation } \\
\text { result can lose } \\
\text { information of thin } \\
\text { cracks in the } \\
\text { images; whereas at } \\
\text { the output with the } \\
\text { relatively low } \\
\text { F-measure values. }\end{array}$ \\
\hline
\end{tabular}

\begin{tabular}{ll}
\hline (Yu et al., & Develop a new \\
& quantitative \\
& physical fatigue \\
& evaluation method \\
& to evaluate the \\
& safety and health \\
& risks in different \\
& construction tasks \\
& arrangements.
\end{tabular}

$\begin{array}{lll}\text { By using deep } & \text { Results showed } & \text { In this study, the } \\ \text { learning } & \text { that the proposed } & \text { 3D motion }\end{array}$

algorithms, biomechanical analysis, and a physical fatigue model. method could assess the physical fatigue level of different construction task conditions such as site layout and the work-rest schedules. estimation method cannot provide accurate $3 \mathrm{D}$ motion estimation when there are severe vision obstructions or under top-down perspectives.

\begin{tabular}{|c|c|c|c|c|}
\hline $\begin{array}{l}\text { (Atha \& } \\
\text { Jahanshahi, } \\
\text { 2018) }\end{array}$ & $\begin{array}{l}\text { This study aims to } \\
\text { examine CNNs for } \\
\text { corrosion } \\
\text { detection of a } \\
\text { sliding window } \\
\text { over an image. }\end{array}$ & $\begin{array}{l}\text { CNN architectures, } \\
\text { ZF Net and } \\
\text { VGG16, were } \\
\text { evaluated and } \\
\text { compared to three } \\
\text { proposed CNNs, } \\
\text { Corrosion7, } \\
\text { Corrosion5, and } \\
\text { VGG15, for } \\
\text { corrosion detection. }\end{array}$ & $\begin{array}{l}\text { CNNs outperforms } \\
\text { the previous state- } \\
\text { of-the-art } \\
\text { corrosion detection } \\
\text { approaches. }\end{array}$ & $\begin{array}{l}\text { The type of } \\
\text { corrosion cannot } \\
\text { be identified, and } \\
\text { the amount of } \\
\text { corrosion cannot } \\
\text { be measured. }\end{array}$ \\
\hline $\begin{array}{l}\text { (Pan et al., } \\
\text { 2018) }\end{array}$ & $\begin{array}{l}\text { This study } \\
\text { presents an } \\
\text { improved } \\
\text { structural } \\
\text { condition }\end{array}$ & $\begin{array}{l}\text { Deep Bayesian } \\
\text { Belief Network } \\
\text { Learning (DBBN). }\end{array}$ & $\begin{array}{l}\text { DBBN could } \\
\text { achieve the high } \\
\text { accuracy in } \\
\text { structural } \\
\text { diagnostics and }\end{array}$ & $\begin{array}{l}\text { There are certain } \\
\text { scatter points in } \\
\text { prediction due to } \\
\text { the high noise } \\
\text { level. }\end{array}$ \\
\hline
\end{tabular}


assessment for

better decision

making for the

complex structures

with uncertainties. can could

accurately

determine the

structural health

state in terms of

damage level.

\begin{tabular}{|c|c|}
\hline $\begin{array}{l}\text { The results show } \\
\text { that there exists } \\
\text { optimal element } \\
\text { size; that is, too } \\
\text { small and too large } \\
\text { element sizes both } \\
\text { increase the } \\
\text { reconstruction } \\
\text { error and decrease } \\
\text { the identification } \\
\text { accuracy. }\end{array}$ & $\begin{array}{l}\text { The capability of } \\
\text { correct } \\
\text { identification } \\
\text { decreases for the } \\
\text { images with low } \\
\text { resolution. }\end{array}$ \\
\hline
\end{tabular}

\section{Deep learning and Ground Penetrating Radar (GPR) to detect cracks}

A few research proposed an integration of GPR and deep learning to detect construction objects and cracks, this enhanced the capabilities and accuracies of the CNN models. Table 4 shows studies that utilize deep learning in conjunction with GPR to detect objects.

Table 4. Deep learning studies based GPR for construction objects detection

\begin{tabular}{|c|c|c|c|c|}
\hline Author & Aim & Methodology & Findings & Limitation \\
\hline $\begin{array}{l}\text { (H. Liu et } \\
\text { al., 2020) }\end{array}$ & $\begin{array}{l}\text { The study aims to } \\
\text { detect and localise } \\
\text { rebar in concrete } \\
\text { using ground } \\
\text { penetrating radar. }\end{array}$ & $\begin{array}{l}\text { Based on the Single } \\
\text { Shot Multibox } \\
\text { Detector (SSD) } \\
\text { model. }\end{array}$ & $\begin{array}{l}\text { The developed SSD } \\
\text { model can detect } \\
\text { rebar with a high } \\
\text { accuracy }(90.9 \% \text {.) in } \\
\text { real time when a } \\
\text { handheld ground } \\
\text { penetrating radar } \\
\text { system is operated at } \\
\text { a walking speed }\end{array}$ & $\begin{array}{l}\text { The study } \\
\text { focuses only on } \\
\text { rebar detection } \\
\text { in concrete; it } \\
\text { can be further } \\
\text { used to detect } \\
\text { other targets, } \\
\text { such as } \\
\text { subsurface } \\
\text { pipes. }\end{array}$ \\
\hline $\begin{array}{l}\text { (Asadi et } \\
\text { al., 2020) }\end{array}$ & $\begin{array}{l}\text { This study aims to } \\
\text { develop a } \\
\text { computer vision- } \\
\text { based rebar } \\
\text { detection chain for } \\
\text { automatic } \\
\text { processing of } \\
\text { concrete bridge } \\
\text { deck GPR images }\end{array}$ & $\begin{array}{l}\text { Fined-tuned } \\
\text { Histogram of } \\
\text { Oriented Gradients/ } \\
\text { Multi-Layer } \\
\text { Perceptron based } \\
\text { binary image } \\
\text { classifier which is } \\
\text { trained on URIGPR } \\
\text { dataset and then } \\
\text { applying a post- } \\
\text { processing algorithm }\end{array}$ & $\begin{array}{l}\text { The obtained } \\
\text { experimental results } \\
\text { indicate that for } \\
\text { classification of } \\
\text { grayscale GPR B- } \\
\text { scan images a } \\
\text { HOG/MLP classifier } \\
\text { outperforms all } \\
\text { studied CNN } \\
\text { models on URIGPR } \\
\text { dataset. }\end{array}$ & $\begin{array}{l}\text { Some False } \\
\text { Negative } \\
\text { detections of } \\
\text { hyperbola } \\
\text { pattern in highly } \\
\text { deteriorated } \\
\text { regions are } \\
\text { observed. }\end{array}$ \\
\hline
\end{tabular}




\section{Discussion, Significance and Limitation}

\begin{tabular}{|c|c|c|c|c|}
\hline $\begin{array}{l}\text { (J. Zhang } \\
\text { et al., } \\
2020)\end{array}$ & $\begin{array}{l}\text { This study aims to } \\
\text { automatically } \\
\text { detect and localize } \\
\text { the moisture } \\
\text { damage area from } \\
\text { GPR B-scan } \\
\text { image to make a } \\
\text { fast and precise } \\
\text { maintenance } \\
\text { decision. }\end{array}$ & $\begin{array}{l}\text { Using mixed deep } \\
\text { convolutional neural } \\
\text { networks (CNN) } \\
\text { including ResNet50 } \\
\text { network, for feature } \\
\text { extraction, and } \\
\text { YOLO v2 network, } \\
\text { for recognition. }\end{array}$ & $\begin{array}{l}\text { The proposed } \\
\text { detection CNN } \\
\text { model shows F1 } \\
\text { score }(91.97 \%) \text {, } \\
\text { Recall }(94.53 \%) \text { and } \\
\text { Precision }(91.00 \%) \text {, } \\
\text { showing that deep } \\
\text { learning is reliable } \\
\text { in detecting and } \\
\text { localising moisture } \\
\text { damages in asphalt } \\
\text { pavements. }\end{array}$ & $\begin{array}{l}\text { To further use } \\
\text { the latest deep } \\
\text { framework to } \\
\text { achieve greater } \\
\text { improvement in } \\
\text { Precision and } \\
\text { Recall. }\end{array}$ \\
\hline $\begin{array}{l}\text { (Lei et al., } \\
\text { 2019) }\end{array}$ & $\begin{array}{l}\text { This study aims to } \\
\text { present an } \\
\text { automatic scheme } \\
\text { for buried objects } \\
\text { detection and } \\
\text { localization. }\end{array}$ & $\begin{array}{l}\text { Combining a trained } \\
\text { deep learning } \\
\text { framework - Faster } \\
\text { R-CNN, } \\
\text { preprocessing } \\
\text { method, DCSE, and } \\
\text { CTFP metho }\end{array}$ & $\begin{array}{l}\text { Comparison with } \\
\text { traditional GPR } \\
\text { shows that this } \\
\text { proposed scheme is } \\
\text { more accurate and } \\
\text { robust in terms of } \\
\text { real-time detection } \\
\text { and localization of } \\
\text { targets in the } \\
\text { experiments. }\end{array}$ & $\begin{array}{l}\text { here is a } \\
\text { redundant } \\
\text { detection } \\
\text { obtained by } \\
\text { Faster R-CN }\end{array}$ \\
\hline
\end{tabular}

\section{Comparison with} traditional GPR shows that this proposed scheme is more accurate and robust in terms of real-time detection and localization of targets in the experiments.

\author{
here is a \\ redundant \\ detection \\ obtained by \\ Faster R-CN
} method, DCSE, and CTFP metho

for removing false detections.

This study provides a comprehensive review in terms of using deep learning to detect a wide range of distresses for pavements and buildings. The papers categorized the utilization of deep learning to two main themes, which are deep learning for pavement distresses and deep learning to evaluate structural health of buildings. The findings are promising, and it has been regonized that deep learning has been successfully implemented to detect a wide range of cracks with a very high level of accuracy. For instance, Elghaish et al. (2021) developed a CNN model that can detect and classify a wide range of cracks with an accuracy more than $97 \%$ and three optimization algorithms were compared in this study to maximize the level of accuracy. With respect to the area of deep learning to evaluate the structural health, there are a few studies compared to pavement's studies and the majority of studies focus on developing solutions to detect and evaluate specific structural elements (e.g., fatigue cracks in steel structures, detect loosened bolts, detect corrosion of a sliding window) rather than presenting an integrated 
evaluation solution-based deep learning.

It was recognized based on the numerous studies that were reviewed that there is a common limitation for most of studies "database size". Thus, further research is needed to develop solutions that can accommodate large size databases and ensure the accuracy of the proposed model in the real-life settings. Moreover, the developments should focus in providing a comprehensive tool, for example, articulating a framework to show the best data collection method, different CNN models according to the type of cracks/distresses and the way of presenting the outcome of the analysis of collected images. This can lead to an integrated maintenance system for highways, steel and concrete buildings.

The utilization of deep learning to assess the health of steel and concrete surfaces was significantly improved, particularly, identifying fatigues, detecting later-load resisting systems, automatically collecting structural information to determine conditions of the complex structures with uncertainties and predicting the damage pattern. However, all attempts did not consider the entire process of data collecting, data analysis-based deep learning CNN models and maintenance decision making system based on the outcome from the deep learning analysis.

Different technologies have been integrated into deep learning to enhance its accuracy (e.g., CNN models), as well as, collecting reliable data (e.g., images of distresses). One of these technologies is GPR that was employed in some studies to (1) detect rebars locations and numbers in the concrete, (2) detect and localize moisture damage in pavements, (3) explore buried objects.

Given, there are many workable deep learning models were developed, however, in order to foster it is implementation, the deep learning models should be integrated into other technologies such as BIM, Internet of Things and Immersive technologies. An example of a 
solution that can be integrated into deep learning is, Sheikhkhoshkar et al. (2019) proposed a 4D BIM-based solution to plan for the concrete joints layout and such model can be integrated into deep leaning to provide an integrated solution.

This research adopted a structured technique that relies on analyzing all articles in the same way to present the focus of study, employed methods, key findings and limitations and thus, allows future researchers to easily find the deficiencies of each tool, how other researchers contributed to solve it, and recommendations to develop further solutions/enhance existing tools. Moreover, this paper provides a solid knowledge base to educators and students that want to adopt deep learning in their curriculum through deciding the optimal approach to be used in their laboratories as well as enabling students to compare between traditional distresses approaches and deep learning or comparing deep learning models.

Due to having a wide range of distresses and this varies from a case to another. Therefore, this article proposes that additional research is needed to compare a wide range of pre-trained deep learning models to identify characteristics that can detect and classify a wide range of distresses precisely, subsequently, more new designated CNN models can be developed based on the characteristics of available data. Moreover, testing each $\mathrm{CNN}$ model against different optimization algorithms to enhance the accuracy of CNN models.

Given, the methodology of this research was applied to specific point, which is the utilization deep learning-based crack detection and articles were analyzed according to their focus of study, methods, contribution/recommendations, and limitations. This structured analysis way provided a deep overview of strengths and weaknesses of employing such technology to detect and classify distresses. As such, another study is recommended to be conducted using the same structured critical analysis method to explore deep learning in other application such as construction site health and safety, equipment detection, energy performance management, etc. 


\section{Conclusion}

This paper provided a state-of-the-art review on the applications of different deep learning techniques to detect and assess distress in both pavements and buildings. Several deep learning tools, techniques and algorithms have been investigated. Those techniques include but are not limited to ANN, CNN, SVM, DBBN, DINN, GPR, etc. Furthermore, applications of those techniques on detecting cracks in pavements and buildings have been discussed and analyzed.

Based on the state-of-the-art review, the future of applying deep learning algorithms as a replacement for manual inspection has shown promising results. The key findings could be summarized as follows: (1) training a customized model with a small amount of data showed high detection accuracy in concrete structures and pavement; (2) quality and amount of data are paramount to enhance the accuracy of cracks' detection and assessment; (3) SVM is capable of detecting data with unrelated patterns; (4) quality of images (e.g. image resolution, lighting conditions, etc.) impacts the accuracy of cracks' detection; and (5) accuracy of the existing models along with the huge time and resources' savings are the key benefits of adopting those algorithms over the manual systems.

Even though, the research has shown promising results for the future of applying deep learning on cracks detection, further research is required to analyze the setup, implementation, and operational costs. Moreover, the optimal frequency of capturing the data shall be investigated to ensure timely detection of the cracks and minimize the operational and data storage costs. Finally, further analysis is required to select the ideal deep learning algorithm while taking into consideration the structure type, available data, etc.

\section{References}

Abdel-Basset, M., Manogaran, G., El-Shahat, D., \& Mirjalili, S. (2018). A hybrid whale optimization algorithm based on local search strategy for the permutation flow shop scheduling problem. 85, 129-145. https://doi.org/10.1016/j.future.2018.03.020

Abdelkader, M. E. (2021). On the hybridization of pre-trained deep learning and differential 
evolution algorithms for semantic crack detection and recognition in ensemble of infrastructures. https://doi.org/10.1108/SASBE-01-2021-0010

Abdel-Qader, I., Pashaie-Rad, S., Abudayyeh, O., \& Yehia, S. (2006). PCA-Based algorithm for unsupervised bridge crack detection. 37(12), 771-778.

https://doi.org/10.1016/j.advengsoft.2006.06.002

Akinosho, T. D., Oyedele, L. O., Bilal, M., Ajayi, A. O., Delgado, M. D., Akinade, O. O., \& Ahmed, A. A. (2020). Deep learning in the construction industry: A review of present status and future innovations. 32. https://doi.org/10.1016/j.jobe.2020.101827

Ali, L., Alnajjar, F., Jassmi, H. A., Gochoo, M., Khan, W., \& Serhani, M. A. (2021). Performance evaluation of deep CNN-based crack detection and localization techniques for concrete structures. 21(5), 1-22. https://doi.org/10.3390/s21051688

Ali, R., \& Cha, Y. J. (2019). Subsurface damage detection of a steel bridge using deep learning and uncooled micro-bolometer. 226, 376-387. https://doi.org/10.1016/j.conbuildmat.2019.07.293

Aljarah, I., Faris, H., \& Mirjalili, S. (2018). Optimizing connection weights in neural networks using the whale optimization algorithm. 22(1). https://doi.org/10.1007/s00500-016-2442-1

Asadi, P., Gindy, M., Alvarez, M., \& Asadi, A. (2020). A computer vision based rebar detection chain for automatic processing of concrete bridge deck GPR data. 112 . https://doi.org/10.1016/j.autcon.2020.103106

Atha, D. J., \& Jahanshahi, M. R. (2018). Evaluation of deep learning approaches based on convolutional neural networks for corrosion detection. 17(5), 1110-1128. https://doi.org/10.1177/1475921717737051

Attoh-Okine, N., \& Ayenu-Prah, A. (2008). Evaluating pavement cracks with bidimensional empirical mode decomposition [Article]. Eurasip Journal on Advances in Signal Processing, 2008, Article 861701. https://doi.org/10.1155/2008/861701

Ayele, Y. Z., Aliyari, M., Griffths, D., \& Droguett, E. L. (2020). Automatic crack segmentation for uav-assisted bridge inspection. 13(23). https://doi.org/10.3390/en13236250

Aziz, M. A. E., Ewees, A. A., \& Hassanien, A. E. (2018). Multi-objective whale optimization algorithm for content-based image retrieval. 77(19), 26135-26172. https://doi.org/10.1007/s11042-018-5840-9

Bae, H., Jang, K., \& An, Y. K. (2021). Deep super resolution crack network (SrcNet) for improving computer vision-based automated crack detectability in in situ bridges. 20(4), 1428-1442. https://doi.org/10.1177/1475921720917227

Cha, Y. J., Choi, W., \& Büyüköztürk, O. (2017). Deep Learning-Based Crack Damage Detection Using Convolutional Neural Networks. 32(5), 361-378. https://doi.org/10.1111/mice.12263

Cha, Y. J., Choi, W., Suh, G., Mahmoudkhani, S., \& Büyüköztürk, O. (2018). Autonomous Structural Visual Inspection Using Region-Based Deep Learning for Detecting Multiple Damage Types. 33(9), 731-747. https://doi.org/10.1111/mice.12334

Chen, F. C., \& Jahanshahi, M. R. (2018). NB-CNN: Deep Learning-Based Crack Detection Using Convolutional Neural Network and Naïve Bayes Data Fusion [Article]. IEEE Transactions on Industrial Electronics, 65(5), 4392-4400, Article 8074762. https://doi.org/10.1109/TIE.2017.2764844

Chen, L.-C., Papandreou, G., Schroff, F., \& Adam, H. (2017). Rethinking Atrous Convolution for Semantic Image Segmentation. ArXiv, abs/1706.05587.

Chen, T., Cai, Z., Zhao, X., Chen, C., Liang, X., Zou, T., \& Wang, P. (2020). Pavement crack detection and recognition using the architecture of segNet. 18 . https://doi.org/10.1016/j.jii.2020.100144

Choudhary, G. K., \& Dey, S. (2012). Crack detection in concrete surfaces using image processing, fuzzy logic, and neural networks. 404-411. https://doi.org/10.1109/ICACI.2012.6463195

Chow, J. K., Su, Z., Wu, J., Li, Z., Tan, P. S., Liu, K. F., Mao, X., \& Wang, Y. H. (2020). Artificial intelligence-empowered pipeline for image-based inspection of concrete structures. 120. https://doi.org/10.1016/j.autcon.2020.103372

Chuang, T. Y., Perng, N. H., \& Han, J. Y. (2019). Pavement performance monitoring and anomaly recognition based on crowdsourcing spatiotemporal data. 106. https://doi.org/10.1016/j.autcon.2019.102882

Chun, P. J., Yamane, T., \& Tsuzuki, Y. (2021). Automatic detection of cracks in asphalt pavement 
using deep learning to overcome weaknesses in images and gis visualization. 11(3), 1-15. https://doi.org/10.3390/app11030892

Da'u, A., \& Salim, N. (2020). Recommendation system based on deep learning methods: a systematic review and new directions. 53(4), 2709-2748. https://doi.org/10.1007/s10462-019-09744-1

Dong, C. Z., Celik, O., Catbas, F. N., O’Brien, E. J., \& Taylor, S. (2020). Structural displacement monitoring using deep learning-based full field optical flow methods. 16(1), 51-71. https://doi.org/10.1080/15732479.2019.1650078

Dorafshan, S., \& Azari, H. (2020). Evaluation of bridge decks with overlays using impact echo, a deep learning approach. 113. https://doi.org/10.1016/j.autcon.2020.103133

Elghaish, F. and Abrishami, S. (2021), "A centralised cost management system: exploiting EVM and $\quad \mathrm{ABC}$ within IPD", Engineering, Construction and Architectural Management, Vol. 28 No. 2, pp. 549-https://doi.org/10.1108/ECAM-11-2019-0623

Elghaish, F., Talebi, S., Abdellatef, E., Matarneh, S. T., Hosseini, M. R., Wu, S., Mayouf, M., Hajirasouli, A., \& Nguyen, T. Q. (2021). Developing a new deep learning CNN model to detect and classify highway cracks. https://doi.org/10.1108/JEDT-04-2021-0192

Fan, C., Sun, Y., Xiao, F., Ma, J., Lee, D., Wang, J., \& Tseng, Y. C. (2020). Statistical investigations of transfer learning-based methodology for short-term building energy predictions. 262. https://doi.org/10.1016/j.apenergy.2020.114499

Fan, C., Sun, Y., Zhao, Y., Song, M., \& Wang, J. (2019). Deep learning-based feature engineering methods for improved building energy prediction. 240, 35-45. https://doi.org/10.1016/j.apenergy.2019.02.052

Fang, F., Li, L., Zhu, H., \& Lim, J. H. (2020). Combining Faster R-CNN and Model-Driven Clustering for Elongated Object Detection. 29(1), 2052-2065. https://doi.org/10.1109/TIP.2019.2947792

Fei, Y., Wang, K. C. P., Zhang, A., Chen, C., Li, J. Q., Liu, Y., Yang, G., \& Li, B. (2020). PixelLevel Cracking Detection on 3D Asphalt Pavement Images through Deep-Learning- Based CrackNet-V. 21(1), 273-284. https://doi.org/10.1109/TITS.2019.2891167

Feng, C., Zhang, H., Wang, H., Wang, S., \& Li, Y. (2020). Automatic pixel-level crack detection on dam surface using deep convolutional network. 20(7). https://doi.org/10.3390/s20072069

Fiorillo, G., \& Nassif, H. (2020). Improving the conversion accuracy between bridge element conditions and NBI ratings using deep convolutional neural networks. 16(12), 1669-1682. https://doi.org/10.1080/15732479.2020.1725065

Ghosh Mondal, T., Jahanshahi, M. R., Wu, R. T., \& Wu, Z. Y. (2020). Deep learning-based multiclass damage detection for autonomous post-disaster reconnaissance. 27(4). https://doi.org/10.1002/stc.2507

Gonzalez, D., Rueda-Plata, D., Acevedo, A. B., Duque, J. C., Ramos-Pollán, R., Betancourt, A., \& García, S. (2020). Automatic detection of building typology using deep learning methods on street level images. 177. https://doi.org/10.1016/j.buildenv.2020.106805

Goodfellow, I., Bengio, Y., \& Courville, A. (2016). Deep Learning. MIT Press url: http://www.deeplearningbook.org

Got, A., Moussaoui, A., \& Zouache, D. (2020). A guided population archive whale optimization algorithm for solving multiobjective optimization problems. 141 . https://doi.org/10.1016/j.eswa.2019.112972

Gou, C., Peng, B., Li, T., \& Gao, Z. (2019). Pavement Crack Detection Based on the Improved Faster-RCNN. 962-967. https://doi.org/10.1109/ISKE47853.2019.9170456

Goulding, J. S., \& Rahimian, F. P. (2012). Industry Preparedness: Advanced Learning Paradigms for Exploitation. In Construction Innovation and Process Improvement (pp. 409-433). WileyBlackwell. https://doi.org/10.1002/9781118280294.ch18

Haciefendioğlu, K., \& Başağa, H. B. (2021). Concrete Road Crack Detection Using Deep LearningBased Faster R-CNN Method. https://doi.org/10.1007/s40996-021-00671-2

Harikarthik, S. K., Palanisamy, V., \& Ramanathan, P. (2019). Optimal test suite selection in regression testing with testcase prioritization using modified Ann and Whale optimization algorithm. 22, 11425-11434. https://doi.org/10.1007/s10586-017-1401-7 
Hasanien, H. M. (2018). Performance improvement of photovoltaic power systems using an optimal control strategy based on whale optimization algorithm. 157, 168-176. https://doi.org/10.1016/j.epsr.2017.12.019

Hassanien, A. E., Elfattah, M. A., Aboulenin, S., Schaefer, G., Zhu, S. Y., \& Korovin, I. (2017). Historic handwritten manuscript binarisation using whale optimisation. 3842-3846. https://doi.org/10.1109/SMC.2016.7844833

He, K., Gkioxari, G., Dollar, P., \& Girshick, R. (2017). Mask R-CNN. 2017-October, 2980-2988. https://doi.org/10.1109/ICCV.2017.322

Heyvaert, M., Hannes, K., \& Onghena, P. . (2017). Using mixed methods research synthesis for literature reviews. SAGE Publications, Inc. . https://doi.org/https://www.doi.org/10.4135/9781506333243

Hoang, N. D., Nguyen, Q. L., \& Tien Bui, D. (2018). Image Processing-Based Classification of Asphalt Pavement Cracks Using Support Vector Machine Optimized by Artificial Bee Colony. 32(5). https://doi.org/10.1061/(ASCE)CP.1943-5487.0000781

Huang, H. W., Li, Q. T., \& Zhang, D. M. (2018). Deep learning based image recognition for crack and leakage defects of metro shield tunnel. 77, 166-176. https://doi.org/10.1016/j.tust.2018.04.002

Huyan, J., Li, W., Tighe, S., Xu, Z., \& Zhai, J. (2020). CrackU-net: A novel deep convolutional neural network for pixelwise pavement crack detection. 27(8). https://doi.org/10.1002/stc. 2551

Huynh, T. C., Park, J. H., Jung, H. J., \& Kim, J. T. (2019). Quasi-autonomous bolt-loosening detection method using vision-based deep learning and image processing. 105. https://doi.org/10.1016/j.autcon.2019.102844

Jenkins, M. D., Carr, T. A., Iglesias, M. I., Buggy, T., \& Morison, G. (2018). A deep convolutional neural network for semantic pixel-wise segmentation of road and pavement surface cracks. 2018-September, 2120-2124. https://doi.org/10.23919/EUSIPCO.2018.8553280

Jiang, Y., \& Bai, Y. (2020). Estimation of Construction Site Elevations Using Drone-Based Orthoimagery and Deep Learning. 146(8). https://doi.org/10.1061/(ASCE)CO.1943$\underline{7862.0001869}$

Jun Zhao, M., Song, B., Fan He, M., Suina Ma, M., \& Fangfang Kong, M. (2020). Asphalt Pavement Crack Detection Based on SegNet Network. 1930-1942. https://www.scopus.com/inward/record.uri?eid=2-s2.085098285065\&partnerID=40\&md5=6688af58b4069bb3953b3bbc513066e4

Kang, D., Benipal, S. S., Gopal, D. L., \& Cha, Y. J. (2020). Hybrid pixel-level concrete crack segmentation and quantification across complex backgrounds using deep learning. 118 . https://doi.org/10.1016/j.autcon.2020.103291

Kim, B., \& Cho, S. (2018). Automated vision-based detection of cracks on concrete surfaces using a deep learning technique. 18(10). https://doi.org/10.3390/s18103452

Kim, B., \& Cho, S. (2019). Image-based concrete crack assessment using mask and region-based convolutional neural network. 26(8). https://doi.org/10.1002/stc.2381

Kim, H., Yoon, J., \& Sim, S. H. (2020). Automated bridge component recognition from point clouds using deep learning. 27(9). https://doi.org/10.1002/stc.2591

Kohiyama, M., Oka, K., \& Yamashita, T. (2020). Detection method of unlearned pattern using support vector machine in damage classification based on deep neural network. 27(8). https://doi.org/10.1002/stc.2552

Kolo, S. J., Rahimian, F. P., \& Goulding, J. S. (2014). Offsite manufacturing construction: A big opportunity for housing delivery in Nigeria. 85, 319-327. https://doi.org/10.1016/j.proeng.2014.10.557

Kumar, B., \& Ghosh, S. (2020). Detection of Concrete Cracks Using Dual-channel Deep Convolutional Network. https://doi.org/10.1109/ICCCNT49239.2020.9225391

Le, T. T., Nguyen, V. H., \& Le, M. V. (2021). Development of deep learning model for the recognition of cracks on concrete surfaces. 2021. https://doi.org/10.1155/2021/8858545

Lee, D., Kim, J., \& Lee, D. (2019). Robust Concrete Crack Detection Using Deep Learning-Based Semantic Segmentation. 20(1), 287-299. https://doi.org/10.1007/s42405-018-0120-5

Lei, W., Hou, F., Xi, J., Tan, Q., Xu, M., Jiang, X., Liu, G., \& Gu, Q. (2019). Automatic hyperbola 
detection and fitting in GPR B-scan image. 106. https://doi.org/10.1016/j.autcon.2019.102839

Li, G., Wan, J., He, S., Liu, Q., \& Ma, B. (2020). Semi-supervised semantic segmentation using adversarial learning for pavement crack detection. 8, 51446-51459. https://doi.org/10.1109/ACCESS.2020.2980086

Li, G., Zhao, X., Du, K., Ru, F., \& Zhang, Y. (2017). Recognition and evaluation of bridge cracks with modified active contour model and greedy search-based support vector machine. 78, 5161. https://doi.org/10.1016/j.autcon.2017.01.019

Li, Q., Zou, Q., Zhang, D., \& Mao, Q. (2011). FoSA: F* Seed-growing Approach for crack-line detection from pavement images [Article]. Image and Vision Computing, 29(12), 861-872. https://doi.org/10.1016/j.imavis.2011.10.003

Li, S., \& Zhao, X. (2019). Image-Based Concrete Crack Detection Using Convolutional Neural Network and Exhaustive Search Technique. 2019. https://doi.org/10.1155/2019/6520620

Li, S., Zhao, X., \& Zhou, G. (2019). Automatic pixel-level multiple damage detection of concrete structure using fully convolutional network. 34(7), 616-634. https://doi.org/10.1111/mice.12433

Liang, X. (2019). Image-based post-disaster inspection of reinforced concrete bridge systems using deep learning with Bayesian optimization. 34(5), 415-430. https://doi.org/10.1111/mice.12425

Ling, Y., Zhou, Y., \& Luo, Q. (2017). Lévy Flight Trajectory-Based Whale Optimization Algorithm for Global Optimization. 5, 6168-6186. https://doi.org/10.1109/ACCESS.2017.2695498

Liu, H., \& Zhang, Y. (2020). Bridge condition rating data modeling using deep learning algorithm. 16(10), 1447-1460. https://doi.org/10.1080/15732479.2020.1712610

Liu, H., Lin, C., Cui, J., Fan, L., Xie, X., \& Spencer, B. F. (2020). Detection and localization of rebar in concrete by deep learning using ground penetrating radar. 118 . https://doi.org/10.1016/j.autcon.2020.103279

Liu, J., Yang, X., Lau, S., Wang, X., Luo, S., Lee, V. C. S., \& Ding, L. (2020a). Automated pavement crack detection and segmentation based on two-step convolutional neural network [Article]. Computer-Aided Civil and Infrastructure Engineering, 35(11), 1291-1305. https://doi.org/10.1111/mice.12622

Liu, J., Yang, X., Lau, S., Wang, X., Luo, S., Lee, V. C. S., \& Ding, L. (2020b). Automated pavement crack detection and segmentation based on two-step convolutional neural network. 35(11), 1291-1305. https://doi.org/10.1111/mice.12622

Machi, L., \& McEvoy, B. (2008). The Literature Review: Six Steps to Success.

Mafarja, M. M., \& Mirjalili, S. (2017). Hybrid Whale Optimization Algorithm with simulated annealing for feature selection. 260,302-312. https://doi.org/10.1016/j.neucom.2017.04.053

Mansuri, L. E., \& Patel, D. A. (2021). Artificial intelligence-based automatic visual inspection system for built heritage. https://doi.org/10.1108/SASBE-09-2020-0139

McGowan, J., \& Sampson, M. (2005). Systematic reviews need systematic searchers. 93(1), 74-80. https://www.scopus.com/inward/record.uri?eid=2-s2.0$18344389065 \&$ partnerID $=40 \& \mathrm{md} 5=\mathrm{d} 0 \mathrm{ccb} 35656745 \mathrm{ab} d 942 \mathrm{ff} 95515955 \mathrm{f} 7 \mathrm{~b}$

Mirjalili, S., \& Lewis, A. (2016). The Whale Optimization Algorithm. 95, 51-67. https://doi.org/10.1016/j.advengsoft.2016.01.008

Mirjalili, S., Mirjalili, S. M., Saremi, S., \& Mirjalili, S. (2020). Whale optimization algorithm: Theory, literature review, and application in designing photonic crystal filters. 811, 219-238. https://doi.org/10.1007/978-3-030-12127-3 13

Mostafa, A., Hassanien, A. E., Houseni, M., \& Hefny, H. (2017). Liver segmentation in MRI images based on whale optimization algorithm. 76(23), 24931-24954. https://doi.org/10.1007/s11042-017-4638-5

Na, W., \& Tao, W. (2012). Proximal support vector machine based pavement image classification. 686-688. https://doi.org/10.1109/ICACI.2012.6463255

Nath, N. D., Behzadan, A. H., \& Paal, S. G. (2020). Deep learning for site safety: Real-time detection of personal protective equipment. 112. https://doi.org/10.1016/j.autcon.2020.103085

Ni, F., Zhang, J., \& Chen, Z. (2019). Pixel-level crack delineation in images with convolutional feature fusion. 26(1). https://doi.org/10.1002/stc.2286

Ogunseiju, O. R., Olayiwola, J., Akanmu, A. A., \& Nnaji, C. (2021). Recognition of workers' actions 
from time-series signal images using deep convolutional neural network. https://doi.org/10.1108/SASBE-11-2020-0170

Ongsulee, P. (2018). Artificial intelligence, machine learning and deep learning. 1-6. https://doi.org/10.1109/ICTKE.2017.8259629

Pan, H., Gui, G., Lin, Z., \& Yan, C. (2018). Deep BBN Learning for Health Assessment toward Decision-Making on Structures under Uncertainties. 22(3), 928-940. https://doi.org/10.1007/s12205-018-1301-2

Pan, Y., Zhang, G., \& Zhang, L. (2020). A spatial-channel hierarchical deep learning network for pixel-level automated crack detection. 119. https://doi.org/10.1016/j.autcon.2020.103357

Patricio, M. A., Maravall, D., Usero, L., \& Rejón, J. (2005). Crack detection in wooden pallets using the wavelet transform of the histogram of connected elements. 8th International Workshop on Artificial Neural Networks, IWANN 2005: Computational Intelligence and Bioinspired Systems, Vilanova i la Geltru.

Pour Rahimian, F., Ibrahim, R., \& Baharudin, M. N. (2008). Using IT/ICT as a new medium toward implementation of interactive architectural communication cultures. International Symposium on Information Technology 2008, ITSim, Kuala Lumpur.

Qiao, W., Zhang, H., Zhu, F., \& Wu, Q. (2021). A Crack Identification Method for Concrete Structures Using Improved U-Net Convolutional Neural Networks. 2021. https://doi.org/10.1155/2021/6654996

Qu, Z., Mei, J., Liu, L., \& Zhou, D. Y. (2020). Crack detection of concrete pavement with crossentropy loss function and improved VGG16 network model. 8, 54564-54573. https://doi.org/10.1109/ACCESS.2020.2981561

Raj, S., \& Bhattacharyya, B. (2018). Optimal placement of TCSC and SVC for reactive power planning using Whale optimization algorithm. 40, 131-143. https://doi.org/10.1016/j.swevo.2017.12.008

Rao, A. S., Nguyen, T., Palaniswami, M., \& Ngo, T. (2021). Vision-based automated crack detection using convolutional neural networks for condition assessment of infrastructure. 20(4), 21242142. https://doi.org/10.1177/1475921720965445

Ren, S., He, K., Girshick, R., \& Sun, J. (2015). Faster R-CNN: Towards real-time object detection with region proposal networks. 2015-January, 91-99.

https://www.scopus.com/inward/record.uri?eid=2-s2.084960980241\&partnerID $=40 \& \mathrm{md5}=18 \mathrm{aaa} 500235 \mathrm{~b} 11 \mathrm{fb} 99 \mathrm{e} 953 \mathrm{f} 8 \mathrm{~b} 227 \mathrm{f} 46 \mathrm{~d}$

Ren, Y., Huang, J., Hong, Z., Lu, W., Yin, J., Zou, L., \& Shen, X. (2020). Image-based concrete crack detection in tunnels using deep fully convolutional networks. 234. https://doi.org/10.1016/j.conbuildmat.2019.117367

Saadi, A., \& Belhadef, H. (2019). Towards an optimal set of initial weights for a deep neural network architecture. 29(6), 403-426. https://doi.org/10.14311/NNW.2019.29.025

Sajedi, S. O., \& Liang, X. (2021). Uncertainty-assisted deep vision structural health monitoring. 36(2), 126-142. https://doi.org/10.1111/mice.12580

Sheikhkhoshkar, M., Pour Rahimian, F., Kaveh, M. H., Hosseini, M. R., \& Edwards, D. J. (2019). Automated planning of concrete joint layouts with 4D-BIM. 107. https://doi.org/10.1016/j.autcon.2019.102943

Shim, S., Kim, J., Cho, G. C., \& Lee, S. W. (2020). Multiscale and adversarial learning-based semisupervised semantic segmentation approach for crack detection in concrete structures. 8 , 170939-170950. https://doi.org/10.1109/ACCESS.2020.3022786

Song, C., Wu, L., Chen, Z., Zhou, H., Lin, P., Cheng, S., \& Wu, Z. (2019). Pixel-Level Crack Detection in Images Using SegNet. 11909 LNAI, 247-254. https://doi.org/10.1007/978-3-030$\underline{33709-422}$

Sri Preethaa, K. R., \& Sabari, A. (2020). Intelligent video analysis for enhanced pedestrian detection by hybrid metaheuristic approach. 24(16), 12303-12311. https://doi.org/10.1007/s00500-020$\underline{04674-5}$

Tong, Z., Yuan, D., Gao, J., \& Wang, Z. (2020). Pavement defect detection with fully convolutional network and an uncertainty framework. 35(8), 832-849. https://doi.org/10.1111/mice.12533

Uijlings, J. R. R., Van De Sande, K. E. A., Gevers, T., \& Smeulders, A. W. M. (2013). Selective search for object recognition. 104(2), 154-171. https://doi.org/10.1007/s11263-013-0620-5 
Wang, K. C. P., Zhang, A., Li, J. Q., Fei, Y., Chen, C., \& Li, B. (2017). Deep Learning for Asphalt Pavement Cracking Recognition Using Convolutional Neural Network. 2017-August, 166177. https://doi.org/10.1061/9780784480922.015

Wang, N., Zhao, Q., Li, S., Zhao, X., \& Zhao, P. (2018). Damage Classification for Masonry Historic Structures Using Convolutional Neural Networks Based on Still Images. 33(12), 1073-1089. https://doi.org/10.1111/mice.12411

Won, D., Chi, S., \& Park, M. W. (2020). UAV-RFID Integration for Construction Resource Localization. 24(6), 1683-1695. https://doi.org/10.1007/s12205-020-2074-y

Xiong, R., \& Tang, P. (2021). Machine learning using synthetic images for detecting dust emissions on construction sites. https://doi.org/10.1108/SASBE-04-2021-0066

Xu, Y., Bao, Y., Chen, J., Zuo, W., \& Li, H. (2019). Surface fatigue crack identification in steel box girder of bridges by a deep fusion convolutional neural network based on consumer-grade camera images. 18(3), 653-674. https://doi.org/10.1177/1475921718764873

Xu, Y., Li, S., Zhang, D., Jin, Y., Zhang, F., Li, N., \& Li, H. (2018). Identification framework for cracks on a steel structure surface by a restricted Boltzmann machines algorithm based on consumer-grade camera images. 25(2). https://doi.org/10.1002/stc.2075

Yang, C., Chen, J., Li, Z., \& Huang, Y. (2021). Structural crack detection and recognition based on deep learning. 11(6). https://doi.org/10.3390/app11062868

Yang, X., Li, H., Yu, Y., Luo, X., Huang, T., \& Yang, X. (2018). Automatic Pixel-Level Crack Detection and Measurement Using Fully Convolutional Network. 33(12), 1090-1109. https://doi.org/10.1111/mice.12412

Ye, X. W., Jin, T., \& Chen, P. Y. (2019). Structural crack detection using deep learning-based fully convolutional networks. 22(16), 3412-3419. https://doi.org/10.1177/1369433219836292

Yu, Y., Li, H., Yang, X., Kong, L., Luo, X., \& Wong, A. Y. L. (2019). An automatic and noninvasive physical fatigue assessment method for construction workers. 103, 1-12. https://doi.org/10.1016/j.autcon.2019.02.020

Zhang, A., Wang, K. C. P., Li, B., Yang, E., Dai, X., Peng, Y., Fei, Y., Liu, Y., Li, J. Q., \& Chen, C. (2017). Automated Pixel-Level Pavement Crack Detection on 3D Asphalt Surfaces Using a Deep-Learning Network. 32(10), 805-819. https://doi.org/10.1111/mice.12297

Zhang, C., Chang, C. C., \& Jamshidi, M. (2020). Concrete bridge surface damage detection using a single-stage detector. 35(4), 389-409. https://doi.org/10.1111/mice.12500

Zhang, H., Tan, J., Liu, L., Wu, Q. M. J., Wang, Y., \& Jie, L. (2017). Automatic crack inspection for concrete bridge bottom surfaces based on machine vision. 2017-January, 4938-4943. https://doi.org/10.1109/CAC.2017.8243654

Zhang, J., Yang, X., Li, W., Zhang, S., \& Jia, Y. (2020). Automatic detection of moisture damages in asphalt pavements from GPR data with deep CNN and IRS method. 113. https://doi.org/10.1016/j.autcon.2020.103119

Zhang, K., Cheng, H. D., \& Zhang, B. (2018). Unified Approach to Pavement Crack and Sealed Crack Detection Using Preclassification Based on Transfer Learning. 32(2). https://doi.org/10.1061/(ASCE)CP.1943-5487.0000736

Zhang, T., Biswal, S., \& Wang, Y. (2020). SHMnet: Condition assessment of bolted connection with beyond human-level performance. 19(4), 1188-1201. https://doi.org/10.1177/1475921719881237

Zhang, X., Rajan, D., \& Story, B. (2019a). Concrete crack detection using context-aware deep semantic segmentation network [Article]. Computer-Aided Civil and Infrastructure Engineering, 34(11), 951-971. https://doi.org/10.1111/mice.12477

Zhang, X., Rajan, D., \& Story, B. (2019b). Concrete crack detection using context-aware deep semantic segmentation network. 34(11), 951-971. https://doi.org/10.1111/mice.12477

Zhao, H., Qin, G., \& Wang, X. (2010). Improvement of canny algorithm based on pavement edge detection. 2010 3rd International Congress on Image and Signal Processing, CISP 2010, Yantai.

Zhou, S., \& Song, W. (2020). Deep learning-based roadway crack classification using laser-scanned range images: A comparative study on hyperparameter selection [Article]. Automation in Construction, 114, Article 103171. https://doi.org/10.1016/j.autcon.2020.103171

Zhou, S., \& Song, W. (2021). Deep learning-based roadway crack classification with heterogeneous 
image data fusion. 20(3), 1274-1293. https://doi.org/10.1177/1475921720948434

Zhou, Y., Wang, F., Meghanathan, N., \& Huang, Y. (2016). Seed-based approach for automated crack detection from pavement images. In Transportation Research Record (Vol. 2589, pp. 162171): National Research Council.

Zhu, J., \& Song, J. (2020). Weakly supervised network based intelligent identification of cracks in asphalt concrete bridge deck. 59(3), 1307-1317. https://doi.org/10.1016/j.aej.2020.02.027

Zhu, S., Du, J., Li, Y., \& Wang, X. (2019). Method for bridge crack detection based on the U-Net convolutional networks. 46(4), 35-42. https://doi.org/10.19665/j.issn1001-2400.2019.04.006

Zhu, S., Xia, X., Zhang, Q., \& Belloulata, K. (2007). An image segmentation algorithm in image processing based on threshold segmentation. 3rd IEEE International Conference on Signal Image Technologies and Internet Based Systems, SITIS'07, Jiangong Jinjiang, Shanghai. 
Comment: 1. The author(s) have stated in their response that "We have also double-checked limitations to avoid subjective judgement."

I'd recommend adding the same statement to the methodology section.

2. The author(s) also have stated in their response that "Authors mentioned [the geographical allocation of publications] in the methodology as an indication for future researcher to know the progress of research in this area over the world."

I'd recommend adding the same statement to the paragraph that explains the figure.

Response: Thanks for your comment: Authors have added two statements as recommended. 